\title{
Angiotensin II-Noradrenergic Interactions in Renovascular Hypertensive Rats
}

\author{
Jeffrey B. Zimmerman, David Robertson, and Edwin K. Jackson \\ Division of Clinical Pharmacology, Department of Pharmacology, Vanderbilt University School of Medicine, Nashville, Tennessee 37232
}

\begin{abstract}
This study tested the hypothesis that interactions of endogenous angiotensin II (AII) with the noradrenergic neuroeffector junction are important in renin-dependent hypertension. In the in situ blood-perfused rat mesentery, in normal rats exogenous AII potentiated mesenteric vascular responses to periarterial (sympathetic) nerve stimulation (PNS) more than vascular responses to exogenous norepinephrine (NE). In 2-kidney-1-clip (2K-1C) rats with renovascular hypertension mesenteric vascular responses to PNS and NE were greater than in sham-operated rats, and renovascular hypertension mimicked the effects of exogenous AII with respect to enhancing responses to PNS more than responses to $\mathrm{NE}$. In $2 \mathrm{~K}-1 \mathrm{C}$ rats, but not in sham-operated rats, 1-Sar-8-Ile-AII markedly suppressed vascular responses to PNS, without influencing responses to NE. Finally, 1-Sar-8Ile-AII attenuated sympathetic nerve stimulation-induced neuronal spillover of $\mathrm{NE}$ in $2 \mathrm{~K}-1 \mathrm{C}$ rats, but not in sham-operated rats. These data indicate that renovascular hypertension enhances noradrenergic neurotransmission, and that this enhancement is mediated in part by AII-induced facilitation of NE release.
\end{abstract}

\section{Introduction}

The role of the renin-angiotensin system in renovascular hypertension has been investigated extensively in laboratory rats. In rats with a normal contralateral kidney, surgically induced ischemia of the ipsilateral kidney (placement of a silver clip on one renal artery, i.e., 2-kidney-1-clip Goldblatt hypertension) causes the development of hypertension via a mechanism primarily dependent on the renin-angiotensin system. In 2-kidney1-clip Goldblatt rats, plasma renin activity increases rapidly (1), and converting enzyme inhibition prevents the onset of hypertension $(2,3)$. Further, the maintenance of an elevated arterial blood pressure in 2-kidney-1-clip Goldblatt rats depends on the renin-angiotensin system for some time after induction of hypertension. Thus, for several weeks after the onset of hypertension, plasma renin activity remains elevated (1) and arterial blood pressure can be normalized by angiotensin II antagonists $(4,5)$, converting enzyme inhibitors $(6,7)$, removal of the ischemic kidney (8), and restoration of renal artery patency (8). As the ravages of hypertension take a toll on the contralateral kidney

Address reprint requests to Dr. Jackson. Dr. Zimmerman's present address is Lockheed Space Company, Department of Bioastronautics, Sunnyvale, CA 94088.

Presented in part at the National Meeting of the American Federation for Clinical Research, Washington, DC, 1983 and 1985. 1987.

Received for publication 24 October 1986 and in revised form 1 April

J. Clin. Invest.

(c) The American Society for Clinical Investigation, Inc.

$0021-9738 / 87 / 08 / 0443 / 15 \quad \$ 2.00$

Volume 80, August 1987, 443-457
(9), however, the importance of the renin-angiotensin system in sustaining the hypertension becomes less clear. Several months into the hypertensive process, plasma renin activity normalizes (1), and angiotensin II antagonists $(4,5)$ or removal of the ischemic kidney $(8,10)$ no longer reverses the hypertension. Considered together, the current body of evidence strongly supports a primary role for the renin-angiotensin system in the development and early maintenance of 2-kidney-1-clip hypertension, with the importance of the renin-angiotensin system gradually waning with time.

Although it is clear that the renin-angiotensin system participates in the development and early maintenance of 2-kidney1-clip hypertension, how the effector molecule, angiotensin II, chronically increases blood pressure is less evident. Angiotensin II has impact on several key domains of the cardiovascular system that influence blood pressure. In addition to the well-known direct vasoconstrictor action of angiotensin II, this peptide also stimulates aldosterone biosynthesis (11), activates the thirst mechanism (12), exerts direct effects on renal mesangial (13) and tubular $(14,15)$ cells, increases sympathetic tone $(16)$, and facilitates noradrenergic neurotransmission (17). Most likely, angiotensin II-induced hypertension is due to a constellation of effects rather than to any one single action.

A critical component of chronic angiotensin II-induced hypertension may be the interaction of this peptide with the sympathetic nervous system. Blood-borne angiotensin II can penetrate into the central nervous system at sites deficient in a bloodbrain barrier, e.g., area postrema, and activate specific receptors that mediate an increase in sympathetic tone (18). This central action of angiotensin II may be reinforced and amplified by a peripheral interaction with noradrenergic neuroeffector junctions. Exogenous angiotensin II facilitates noradrenergic neurotransmission by enhancing depolarization-induced norepinephrine release $(19,20)$, blocking the uptake of norepinephrine into sympathetic varicosities, i.e., uptake $-1(21,22)$, and augmenting the postjunctional response to norepinephrine (23). It is anticipated that these actions of angiotensin II, especially when combined with an increased sympathetic tone, would contribute significantly to the hypertensionogenic action of angiotensin II. That this is the case with exogenous angiotensin II can be inferred from experiments demonstrating that chronic infusions of immediately subpressor doses of angiotensin II cause a gradual rise in arterial blood pressure that is reversed by noradrenergic neuronal blocking drugs (24).

Although the interaction of exogenous angiotensin II with noradrenergic neuroeffector junctions has been acknowledged for over 20 years (25), the hypothesis remains untested that elevated levels of angiotensin II associated with sustained renovascular hypertension facilitate noradrenergic neurotransmission. To our knowledge, the only full length publication addressing this issue reported studies conducted only after acute renal artery stenosis in the dog (26). Accordingly, we carried to fruition a series of studies designed to test the hypothesis that elevated levels of angiotensin II associated with renovascular hypertension facilitate noradrenergic neurotransmission. This 
hypothesis was initially tested by comparing the effects of angiotensin II and chronic renovascular hypertension on vascular responses to sympathetic nerve stimulation and norepinephrine in the autoperfused rat mesenteric vascular bed. The hypothesis was tested further by determining the effects of antagonism of angiotensin II receptors on mesenteric vascular responses to sympathetic nerve stimulation and norepinephrine in renovascular hypertensive and sham-operated rats. Finally, we examined the effects of angiotensin-receptor antagonism on the neuronal spillover of endogenous norepinephrine from the mesenteric vascular bed using a novel technique specifically designed for these experiments. Taken as a whole, our results indicate that renovascular hypertension enhances the vascular response to sympathetic nerve stimulation and that this enhancement is mediated in part by AII-induced facilitation of NE release. These studies demonstrate for the first time the importance of angiotensin II-noradrenergic interactions in chronic renovascular hypertension.

\section{Methods}

\section{Preparation of 2-kidney-1-clip $(2 K-1 C)^{1}$ renovascular hypertensive rats}

Male Sprague-Dawley rats (175-225 g) were anesthetized with pentobarbital ( $50 \mathrm{mg} / \mathrm{kg}$, i.p.), and the left kidney was exposed. In some rats, a silver clip ( $0.25 \mathrm{~mm}$ gap) was permanently installed around the left renal artery ( $2 \mathrm{~K}-1 \mathrm{C}$ rats), and in other rats a clip was temporarily placed around the renal artery and then removed (sham-operated rats). The abdominal cavity was sutured with 4.0 silk, and the skin was held together using 9-mm wound clips (Clay Adams, Parsippany, NJ). All animals were allowed to recover for $3 \mathrm{wk}$. Animals were maintained on a diet containing 170 meq Na${ }^{+} / \mathrm{kg}$ and $246 \mathrm{meq} \mathrm{K}+/ \mathrm{kg}^{+}$(Allied Mills, Chicago, IL) and were given tap water ad lib. Animals were housed in a facility that provided a constant temperature $\left(22^{\circ} \mathrm{C}\right)$ and a 12 -h light/dark cycle (6:00 a.m. $-6: 00$ p.m.).

\section{Tail cuff measurement of systolic blood pressure}

Systolic blood pressures were determined 3 wk after surgery. Rats were kept in a $33^{\circ} \mathrm{C}$ environment (heating pad in a plastic rat cage) for 10 min. Each animal was then placed in a heated animal restrainer (Narco, Houston, TX). A cuff was placed around the base of the animal's tail, and a pneumatic sensor was taped in place over the tail artery. Using an electro-sphygmomanometer (model PE-300, Narco), the cuff around the rat's tail was repeatedly inflated and deflated $(17.5 \mathrm{mmHg} / \mathrm{s}$, every $30 \mathrm{~s}$ ) for $10 \mathrm{~min}$. This procedure enabled the animal to habituate to the system. Blood pressure measurements were then recorded. During cuff inflation and deflation, the point of pulse-pressure dampening was read from the chart paper for three consecutive cycles. Systolic blood pressure was then calculated as the mean of these six values. The criterion for classifying $2 \mathrm{~K}-1 \mathrm{C}$ and sham-operated animals was as follows: clipped animals having a systolic blood pressure greater than or equal to 165 $\mathrm{mmHg}$ were classified as $2 \mathrm{~K}-1 \mathrm{C}$ renovascular hypertensive rats. Shamoperated animals having a systolic blood pressure less than or equal to $150 \mathrm{mmHg}$ were classified as normotensive. All other animals were not studied.

Validation of the $2 K-1 C$ animal as an elevated renin model $12 \mathrm{~K}-1 \mathrm{C}$ rats (3 wk postclipping) and 12 sham-operated animals were moved to a quiet room and animals (chosen randomly between $2 \mathrm{~K}-1 \mathrm{C}$ and sham-operated groups) were transferred one at a time to an adjacent

1. Abbreviations used in this paper: ANOVA, analysis of variance; EPI, epinephrine; NE, norepinephrine; PNS, periarterial nerve stimulation; PRA, plasma renin activity; 2K-1C, 2 kidney-1 clip. room. The rat was killed rapidly by decapitation. Blood $(3 \mathrm{ml})$ for plasma renin activity (PRA) was collected during the first $3 \mathrm{~s}$ after decapitation into a prechilled $\left(4^{\circ} \mathrm{C}\right) 10 \mathrm{ml}$ polypropylene tube containing $15 \mathrm{mg}$ EDTA. Blood for plasma angiotensin I levels was collected during the second $3 \mathrm{~s}(2 \mathrm{ml})$ after decapitation into a $10-\mathrm{ml}$ polypropylene tube containing EDTA, pepstatin, and nonapeptide converting enzyme inhibitor ( $15 \mathrm{mM}, 10 \mu \mathrm{M}$, and $23 \mu \mathrm{M}$ final concentration, respectively).

Blood was centrifuged at $2,000 \mathrm{~g}$ at $4^{\circ} \mathrm{C}$ for $15 \mathrm{~min}$. The rat plasma was transferred in a cold room to 5-ml polypropylene tubes and stored at $-70^{\circ} \mathrm{C}$. PRA and plasma angiotensin I levels were determined by the method of Workman et al. as previously described (27).

\section{Preparation of animals for in situ perfusion of the mesenteric vasculature}

3 wk after surgery, each rat was anesthetized with pentobarbital $(50 \mathrm{mg} /$ kg, i.p.) and prepared for in situ blood perfusion of the mesenteric vascular bed using a modification of the technique described by Jackson and Campbell (28). An incision was made in the neck, and cannulas were placed into the right jugular vein (PE-50, Clay Adams) and the trachea (PE-240, Clay Adams). The animal was maintained on a pentobarbital infusion $(0.375 \mathrm{mg} / \mathrm{kg}$ per $\mathrm{min})$ via the right jugular cannula throughout the experiment.

The rat was secured to a Plexiglas board, and a laparotomy was performed. The intestines were exteriorized and covered with cotton gauze moistened with $0.9 \%$ saline. The abdominal aorta caudal to the left renal artery was isolated, and two 4.0 sutures were placed, but not tied, around the artery. The superior mesenteric artery was isolated 5 $\mathrm{mm}$ from the junction with the abdominal aorta, and two sutures were placed loosely around the mesenteric artery. The tissue and nerves surrounding the mesenteric artery were isolated, and a suture was placed around the bundle. The mesenteric nerves entering the surrounding tissue of the superior mesenteric artery were then severed. The abdominal area was covered with saline-moistened gauze and kept warm under a 75-W light.

A 45-min rest period was allowed to give time for small bleeders to clot. Following the rest period, $1.5 \mathrm{ml}$ of heparin $(1,000 \mathrm{U} / \mathrm{ml}$ ElkinsSinn, Inc., Cherry Hill, NJ) was infused into the jugular vein. A 6-in cannula (PE-90, Clay Adams) was filled with normal saline and clamped with forceps at one end. The suture on the distal aorta was tied securely, and a small vascular clamp was placed on the proximal portion of the isolated aorta. A small incision was cut into the aorta distal to the vascular clamp, and the PE-90 cannula was inserted into the vessel. The proximal aortic tie was then secured around the vessel, and the vascular clamp was removed.

The rat and board unit were transferred to the top of a Harvard peristaltic infusion system equipped with the perfusion cannula detailed in Fig. 1 and Table I. Pressure transducers (model RP-1500i, Narco) were connected to cannulas T2 and T9 for monitoring arterial blood pressure and mesenteric perfusion pressure, respectively. The PE-90 cannula from the aorta was cut to 3 in and inserted into T1 of the perfusion cannula (Fig. 1). The peristaltic pump was turned on to purge the cannula at $\mathrm{T} 10$ of air and then immediately turned off. The proximal suture around the mesenteric artery was secured to occlude the vessel. While pulling on the distal suture, a nick was cut into the mesenteric artery between the two sutures. A PE-50 cannula attached to T10 was then inserted into the artery. The distal suture was tied around the mesenteric artery and cannula to secure the cannula in place. The peristaltic pump was immediately switched on, and perfusion was begun at $3.0 \mathrm{ml} /$ min. The cannulation of the mesenteric artery, following occlusion of the artery, took place within $2 \mathrm{~min}$, thereby preventing degradation and instability of the preparation.

A bipolar platinum electrode was then placed around the mesenteric artery including the periarterial nerves $1 \mathrm{~cm}$ from the aortic junction, and cotton gauze moistened with normal saline was placed over the abdominal opening and exteriorized intestines. Throughout the experiment, the preparation was kept warm with a 75-W light aimed over the animal and was kept moist by continual application of normal saline to 


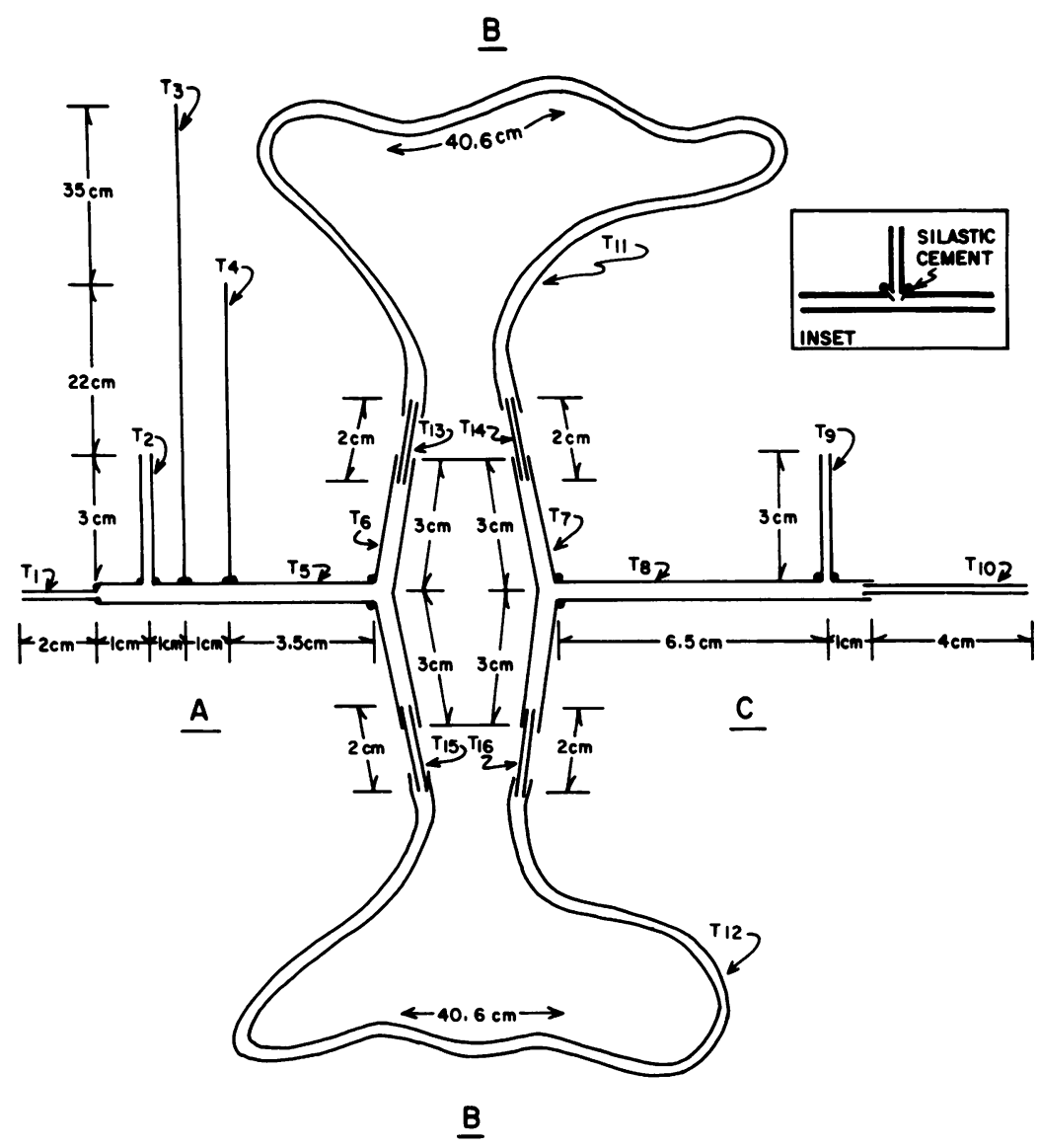

Figure 1. Physical arrangement of perfusion cannula. See Table I for dimensions and descriptions of labeled parts. the cotton gauze. An infusion of $0.9 \%$ saline $(0.05 \mathrm{ml} / \mathrm{min})$ or $0.9 \%$ saline containing angiotensin peptides $(0.05 \mathrm{ml} / \mathrm{min})$ was maintained at all times into cannulas $\mathrm{T} 3$ and $\mathrm{T} 4$, respectively. For a diagram of the in situ perfused rat mesentery see Fig. 2.

Vascular responses (i.e., changes in perfusion pressure) to periarterial nerve stimulation (PNS) were elicited by stimulating the mesenteric periarterial nerves with 20 -s trains of bipolar pulses $(1.0 \mathrm{~ms}$ pulse duration, $34.0 \mathrm{~V}$ amplitude) at 3,5, and $7 \mathrm{~Hz}$. After each stimulation, there was

Table I. Part Description for the Mesenteric Perfusion Cannula

\begin{tabular}{lllll}
\hline Part No. & ID & OD & Length & Material \\
\hline & in. & in. & cm & \\
T1 & 0.040 & 0.085 & 2.0 & Silastic \\
T2 & 0.062 & 0.094 & 3.0 & Silastic \\
T3 & 0.020 & 0.037 & 60.0 & Silastic \\
T4 & 0.020 & 0.037 & 25.0 & Silastic \\
T5 & 0.062 & 0.125 & 6.5 & Silastic \\
T6, T7 & 0.062 & 0.125 & 6.0 & Silastic \\
T8 & 0.062 & 0.125 & 7.5 & Silastic \\
T9 & 0.062 & 0.094 & 3.0 & Silastic \\
T10 & 0.040 & 0.085 & 4.0 & Silastic \\
T11, T12 & 0.045 & - & 40.6 & Flexible PVC \\
T13, T14 & $15 \mathrm{~g}$ & - & 2.0 & Stainless needle \\
T15, T16 & & & & \\
\hline
\end{tabular}

Silastic, Dow Corning Medical Grade Tubing. Flexible PVC, FISHERbrand Technicon Manifold Pump Tubing. Stainless Needle, Clay Adams Intramedic Luer Stub Adapter. a 3-min rest period. PNS always occurred in ascending order $(3,5$, and $7 \mathrm{~Hz}$ ) and always preceded the dose-response curve to norepinephrine. This order was chosen to avoid any residual effects of injected norepinephrine on responses to PNS due to activation of prejunctional alpha ${ }_{2}$ adrenoceptors.

Vascular responses to norepinephrine (NE; 100, 200, and $300 \mathrm{ng}$ ) also were determined in ascending order. NE in a volume of $100 \mu \mathrm{l}$ of $0.9 \%$ saline was loaded into cannula T3 (Fig. 1), and the NE solution was then flushed into the perfusion system with normal saline $(150 \mu \mathrm{l})$. After each dose of agonist, the return to baseline was followed by a 3min rest period. Vascular responses were recorded on a polygraph (model 79, Grass Instrument Co., Quincy, MA) and were measured as the peak height relative to the baseline preceding the stimulus.

\section{Protocols using in situ perfusion of mesenteric vasculature}

In one group $(n=7)$ of unoperated normal animals ( $\mathrm{N}$ group), responses to PNS and NE were determined in a control period, in the presence of angiotensin II, and in the presence of both angiotensin II and 1-Sar-8Ile-AII as follows. $3 \mathrm{~min}$ after the last NE dose in the control period, an infusion $(0.05 \mathrm{ml} / \mathrm{min})$ of angiotensin II $(9 \mathrm{ng} / \mathrm{min}$; dissolved in saline) was initiated directly into the mesenteric artery. $15 \mathrm{~min}$ into the angiotensin II infusion, vascular responses to PNS and NE were redetermined. Next, an infusion of 1-Sar-8-Ile-AII $(150 \mathrm{ng} / \mathrm{min})$ was added to the angiotensin II infusion, and mesenteric vascular responses were again determined $30 \mathrm{~min}$ into this combined infusion of angiotensin II and 1Sar-8-Ile-AII.

In a group of $2 \mathrm{~K}-1 \mathrm{C}$ animals $(n=11)$, control responses to PNS and $\mathrm{NE}$ were determined. After responses to NE had been elicited, in 6 of the 11 animals the angiotensin II antagonist, 1-Sar-8-Ile-AII $(150 \mathrm{ng} /$ min, dissolved in $0.9 \%$ saline), was infused at $0.05 \mathrm{ml} / \mathrm{min}$ directly into the mesenteric artery. In the remaining 5 of the 11 animals, vehicle (0.9\% saline) was infused instead. $30 \mathrm{~min}$ into the infusion of either 1Sar-8-Ile-AII or vehicle, responses to PNS and NE were repeated. An 


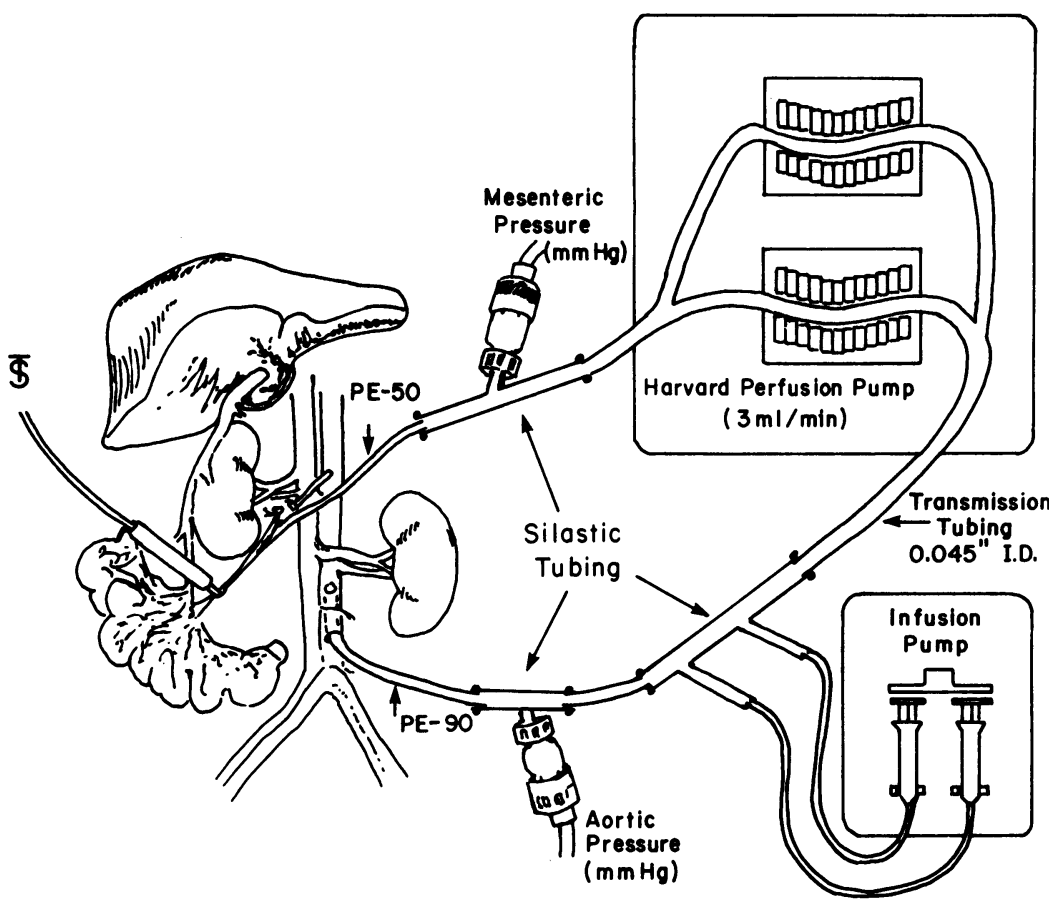

Figure 2. Diagram illustrating the in situ perfused rat mesentery. A polyethylene cannula (PE-90) is placed into the aorta distal to the left renal artery and is connected to the perfusion circuit, which courses extracorporeally through a Harvard peristaltic pump and reenters the circulation at the mesenteric artery. Blood flows from the aorta to the mesenteric artery at $3 \mathrm{ml} /$ $\mathrm{min}$. Both aortic pressure and mesenteric perfusion pressure are monitored. Mesenteric perfusion pressure responses are determined by either electrically stimulating the mesenteric periarterial nerves or injecting norepinephrine into the extracorporeal circuit. (Figure adapted from Jackson and Campbell, 1979, by permission from publisher.) identical protocol was conducted also in a group $(n=11)$ of shamoperated animals.

\section{Determination of $N E$ spillover from the mesenteric vascular bed of $2 \mathrm{~K}-1 \mathrm{C}$ and sham-operated animals}

Method and protocol. The experiments described above were designed to examine the effects of AII receptor blockade on vascular responses to PNS and NE. We also wished to explore the effects of AII receptor blockade on NE spillover. Ideally, we would have preferred measuring NE spillover in the same system described above, i.e., the in situ bloodperfused rat mesentery. However, it was realized that the loss of blood due to the blood sampling and the dead space in the extracorporeal perfusion $(1.5 \mathrm{ml})$ would probably have given rise to high circulating levels of NE. If so, detection of NE release from the mesentery during PNS would have been difficult. For these reasons, we chose a different paradigm for measuring the effects of AII receptor blockade on NE spillover.

3 wk after either renal artery clipping or sham operation, rats were anesthetized with pentobarbital $(50 \mathrm{mg} / \mathrm{kg}$, i.p.) and secured to a Plexiglas board. Cannulas were placed in the trachea (PE-240), the jugular vein (PE-50), the left ventricle (PE-50) via the right carotid artery, the femoral artery (PE-50), and the femoral vein (PE-50). Animals were maintained on a pentobarbital infusion $(0.375 \mathrm{mg} / \mathrm{kg}$ per $\mathrm{min})$ into the jugular vein over the course of the experiment.

Next, a laparotomy was performed, and the superior mesenteric artery was isolated $5 \mathrm{~mm}$ from its junction with the abdominal aorta, and two sutures were placed around the mesenteric artery but were not tied. The tissue surrounding the mesenteric artery, including the mesenteric nerves, was isolated, and the superior mesenteric nerves were severed, and a suture was placed around the nerve bundle to enable placement of a bipolar electrode.

The mesenteric vein was gently cleared of connective tissue, and a 22-gauge needle connected to silastic tubing was inserted into the mesenteric vein against mesenteric flow. Superglue (Duro Corp., Cleveland, $\mathrm{OH}$ ) was placed around the needle to prevent slippage, and the cannula was filled with heparinized saline $(100 \mathrm{U} / \mathrm{ml})$. A 30-gauge needle formed into a hook was connected to silastic tubing, and the 30-gauge needle was inserted into the mesenteric artery in the direction of blood flow. A bipolar electrode was then placed around the mesenteric nerve-artery bundle $1 \mathrm{~cm}$ from the aortic junction, and the electrode was attached to a stimulator (model SD-5, Grass Instrument Co.) set at $1.0 \mathrm{~ms}$ pulse duration, $34.0 \mathrm{~V}$, and bipolar pulses. Cotton gauze moistened with $0.9 \%$ saline was placed over the abdominal cavity and exteriorized intestines, and was kept moist throughout the experiment. The animals were kept warm with a 75-W lamp.

After a 45-min postsurgical rest period, either 1-Sar-8-Ile-AII (300 $\mathrm{ng} / \mathrm{min}$ ) or vehicle $(0.9 \%$ saline, $0.05 \mathrm{ml} / \mathrm{min})$ was infused into the mesenteric artery via the 30 -gauge needle. Six $2 \mathrm{~K}-1 \mathrm{C}$ rats and six shamoperated rats received 1-Sar-8-Ile-AII, and six $2 \mathrm{~K}-1 \mathrm{C}$ and six sham-operated rats received vehicle. The dose of 1-Sar-8-Ile-AII was increased from $150 \mathrm{ng} / \mathrm{min}$ to $300 \mathrm{ng} / \mathrm{min}$ in these experiments since the mesenteric blood flow in a normal rat is $\sim 5 \mathrm{ml} / \mathrm{min}$, compared with $3 \mathrm{ml} / \mathrm{min}$ in the extracorporeal system.

The experiment was divided into two periods separated by $20 \mathrm{~min}$. For half of the 2K-1C animals and sham-operated rats, period 1 consisted of periarterial nerve stimulation $(5 \mathrm{~Hz}$, for $3 \mathrm{~min}$ ), and period 2 was a control period. In the remaining half of the $2 \mathrm{~K}-1 \mathrm{C}$ animals and shamoperated rats, period 1 was a control period and period 2 was a stimulation period.

Period 1 began $1 \mathrm{~h}$ into the infusion of either 1-Sar-8-Ile-AII or vehicle. Period 2 began after a 20-min rest after period 1 . Both periods 1 and 2 consisted of injection of radiolabeled microspheres into the left ventricle via the right carotid artery. Blood samples from the femoral artery and the mesenteric vein were withdrawn simultaneously with the injection of radiolabeled microspheres.

Blood withdrawal and microsphere injection began $1 \mathrm{~min}$ after the onset of periarterial nerve stimulation. Microspheres were injected and flushed through the ventricular cannula over $1 \mathrm{~min}$, whereas blood was withdrawn during the last $2 \mathrm{~min}$ of nerve stimulation. Each control period was initiated by a 2 -min blood withdrawal and a 1-min microsphere injection and flush in the absence of periarterial nerve stimulation.

The femoral artery sample was used for determination of microsphere content and for arterial catecholamine analysis. The mesenteric vein sample was used for determination of mesenteric venous catecholamine concentration. At the end of each 2-min blood withdrawal period, blood volume was replaced with $2 \mathrm{vol}$ of $0.9 \%$ saline administered into the femoral vein.

Femoral artery blood was withdrawn via a Harvard withdrawal pump at a rate of $0.45 \mathrm{ml} / \mathrm{min}$ into a $1-\mathrm{ml}$ syringe to a total volume of $0.9 \mathrm{ml}$. Mesenteric venous blood was also withdrawn into a $1-\mathrm{ml}$ syringe, but 
to a total volume of $0.5 \mathrm{ml}$. Both syringes were preloaded with a glutathione-EGTA solution $(20 \mu \mathrm{l} / \mathrm{ml}$ blood) to prevent catecholamine degradation.

Radiolabeled microspheres tagged with different isotopes $\left({ }^{141} \mathrm{Ce}\right.$ or ${ }^{88} \mathrm{Sr}$ ) were used for each of the injection periods. Microspheres $(3 \mathrm{M}$ Company, St. Paul, MN, $2.0 \times 10^{5}$ spheres $/ \mathrm{ml}, 5.4 \mu \mathrm{Ci} / \mathrm{ml}, 15 \mu \mathrm{m}$ ) were suspended in $0.9 \%$ saline. The microsphere solution was placed in a sonicator for $5 \mathrm{~min}$ and subjected to vigorous shaking (vortex) for $1 \mathrm{~min}$ before injection. Microspheres $(0.5 \mathrm{ml})$ were drawn into a $1-\mathrm{ml}$ syringe equipped with a 20 gauge blunt needle. The microsphere-saline suspension was injected slowly into the ventricular cannula over $30 \mathrm{~s}$. The ventricular cannula was then flushed with $0.5 \mathrm{ml}$ of normal saline over an additional $30 \mathrm{~s}$.

At the end of the 2-min blood withdrawal period, a sample for hematocrit determination was taken from the femoral artery cannula, and reference blood flow counts were determined by counting the femoral artery sample and the PE-50 tubing used to withdraw the blood sample (autogamma scintillation spectrometer, Packard Instrument Co., Inc., Downers Grove, IL). The mesenteric venous samples were placed in a glass tube and stored on ice. After counting, the arterial sample was placed in a glass tube and stored on ice. All samples were centrifuged $(1,000 \mathrm{~g})$ for $20 \mathrm{~min}$ at $4^{\circ} \mathrm{C}$. The plasma was stored at $-70^{\circ} \mathrm{C}$ and later assayed for norepinephrine and epinephrine concentrations.

The catecholamine content of plasma samples was determined according to the methodology of Peuler and Johnson (29). Analysis was facilitated by the use of the CAT-A-KIT catecholamines radioenzymatic assay kit (The Upjohn Co., Kalamazoo, MI).

At the end of the experiment, the mesentery and the small intestines (from the stomach to the cecum) were excised from the animal and flushed with normal saline to clean out the bowel contents. The mesentery and the small intestines were weighed, and their radioactivity determined by gamma scintillation spectrometry. Suitable energy window settings were used for each microsphere isotope. Counts were corrected for overlap of energy spectra, and blood flow to the mesentery was determined using previously published equations (30). Neuronal spillover of NE from the in vivo rat mesentery was then calculated as described below.

\section{Calculation of neuronal $N E$ spillover}

By knowing the mesenteric blood flow, hematocrit, and plasma levels of $\mathrm{NE}$ in the mesenteric venous blood $\left(\mathrm{NE}_{\mathrm{V}}\right)$ and arterial blood $\left(\mathrm{NE}_{\mathbf{2}}\right)$ the spillover of NE from the mesentery can be calculated by the formula:

$\mathrm{NE}$ spillover $=\left(\mathrm{NE}_{\mathrm{v}}-\mathrm{NE}_{\mathrm{a}}\right) \times$ mesenteric blood flow $\times(1-\mathrm{Hct})$

This is the traditional formula for calculating the spillover of NE from sympathetic nerves innervating a tissue. However, the NE spillover calculated using Eq. 1 may not be accurate. By subtracting out the arterial level of NE from the venous level, one is assuming that all of the NE entering the tissue gains access to the venous drainage of that tissue. Clearly, this is not the case since some NE is removed by the tissue as it makes a transit through the tissue. Therefore, this formula underestimates the true spillover of NE from sympathetic nerve endings within the tissue.

Another approach used to calculate the spillover of NE from sympathetic nerves is to assume that none of the arterial NE escapes tissue clearance, and therefore one need not subtract the arterial levels of NE from the venous levels, i.e.:

$\mathrm{NE}$ spillover $=\mathrm{NE}_{\mathrm{v}} \times$ mesenteric blood flow $\times(1-\mathrm{Hct})$

This approach also may not be accurate since the assumption that most of the arterial input of NE is cleared by the tissue may not be valid.

As an alternate approach to calculating the spillover of NE from sympathetic nerves in a tissue, we use a technique that takes into consideration the percentage of arterial NE that escapes clearance and appears in the venous drainage of a tissue. The formula that we advocate is:

$\mathrm{NE}$ spillover $=\left(\mathrm{NE}_{\mathrm{v}}-k \mathrm{NE}_{\mathrm{a}}\right) \times$ mesenteric blood flow $\times(1-\mathrm{Hct})$
In this formula the coefficient $k$ is the fraction of arterial NE that escapes tissue clearance and appears in the venous drainage. Note that this formula reduces to Eq. 1 if it is assumed that $k$ is 1 (i.e., that all the arterial NE ends up in the venous drainage) and reduces to Eq. 2 if it is assumed that $k$ is 0 (i.e., that none of the arterial NE ends up in the venous drainage). Eq. 3 allows calculation of the true amount of $\mathrm{NE}$ that is released by the nerve endings and escapes into the venous drainage (i.e., the amount of NE that is released from nerve endings and escapes uptake and metabolism). Although this calculated spillover cannot be equated with the actual release rate of $\mathrm{NE}$, the spillover calculated by this technique should be closer to this quantity than is the NE spillover calculated by Eqs. 1 and 2.

To use Eq. 3 it is necessary to know the true value for $k$. One approach for determining $k$ is to assume that the fraction of arterial epinephrine that escapes tissue clearance is the same as that for norepinephrine. Since epinephrine levels can be measured in the mesenteric vein and femoral artery of each rat, if this assumption is true then one could calculate $k$ for each rat as: $k=$ Epinephrine level in vein/Epinephrine level in artery.

Fortunately, the assumption that NE clearance is similar to epinephrine clearance in the rat mesentery is valid, both under basal conditions and during sympathetic nerve stimulation (see below). Therefore, in these studies we calculated NE spillover using Eq. 3 by estimating the value of $k$ from the level of epinephrine (EPI) in the mesenteric vein and aorta. The validity of the assumption that the clearance of NE and EPI are similar in the rat mesentery was determined as described below.

Six male Sprague-Dawley rats $(300 \mathrm{~g})$ were divided into two groups. Cannulas were placed into the jugular vein, trachea, left ventricle, femoral artery, femoral vein, and mesenteric vein as described above for the spillover experiments. A bipolar electrode was placed around the periarterial nerves. The bipolar electrode was connected to a stimulator (model SD-5, Grass Instrument Co.) set at $5 \mathrm{~Hz}, 1.0 \mathrm{~ms}$ pulse duration, and $34.0 \mathrm{~V}$. A continuous infusion of pentobarbital $(0.375 \mathrm{mg} / \mathrm{kg}$ per $\mathrm{min})$ was administered into the jugular vein. A 1-h stabilization period followed.

For rats in group 1, a control (no stimulation) period was followed 30 min later by a stimulation period; rats in group 2 received these treatments in the reverse order. In the control period, $\left[{ }^{3} \mathrm{H}\right] \mathrm{NE}$ (sp act $53.5 \mathrm{Ci} / \mathrm{mmol})$ and $\left[{ }^{3} \mathrm{H}\right] \mathrm{EPI}(\mathrm{sp}$ act $74.9 \mathrm{Ci} / \mathrm{mmol})$ were infused $(25.7$ $\mu \mathrm{Ci}$ of each isotope in a total volume of $3 \mathrm{ml}$ of $0.9 \%$ saline) into the left ventricle over $2 \mathrm{~min} .1 \mathrm{~min}$ into the infusion, and during the remaining $1 \mathrm{~min}$ of the infusion, blood was withdrawn from both the femoral artery $(0.5 \mathrm{ml})$ and mesenteric vein $(0.5 \mathrm{ml})$ into a $1-\mathrm{ml}$ syringe previously loaded with a 10- $\mu$ l aliquot of an EGTA-glutathione solution $(95 \mathrm{mg}$ EGTA, $60 \mathrm{mg}$ reduced glutathione per ml solution, $\mathrm{pH} 6.5,20 \mu \mathrm{l} / \mathrm{ml}$ blood).

During the stimulation period, the periarterial nerves were stimulated $(5 \mathrm{~Hz}$ ) for $3 \mathrm{~min}$. After $1 \mathrm{~min}$ of periarterial nerve stimulation, an infusion of $\left[{ }^{3} \mathrm{H}\right] \mathrm{NE}$ and $\left[{ }^{3} \mathrm{H}\right] \mathrm{EPI}$ into the left ventricle was commenced and continued for the remaining $2 \mathrm{~min}$. Blood was withdrawn from both the femoral artery and mesenteric vein during the last minute of catecholamine infusion.

Blood samples were kept on ice until the end of the experiment, at which point plasma was separated from blood by centrifugation $(1,000$ $g, 4^{\circ} \mathrm{C}$ ) and was stored at $-70^{\circ} \mathrm{C}$ for later determination of $\left[{ }^{3} \mathrm{H}\right] \mathrm{NE}$ and $\left[{ }^{3} \mathrm{H}\right] \mathrm{EPI}$.

Mesenteric venous plasma and femoral arterial plasma collected during the infusion of $\left[{ }^{3} \mathrm{H}\right] \mathrm{NE}$ and $\left[{ }^{3} \mathrm{H}\right] \mathrm{EPI}$ were processed as follows. Plasma $(200 \mu \mathrm{l})$ was placed in a 5 -ml conical reaction vial containing $50 \mathrm{mg}$ acid-washed aluminum oxide. A 1-ml portion of Tris buffer/ EDTA ( $45 \mathrm{~g}$ Tris base and $5 \mathrm{~g} \mathrm{Na}$ EDTA in $250 \mathrm{ml}$ distilled water adjusted to $\mathrm{pH} 8.6$ with $\mathrm{HCl}$ ) was added to the reaction vial. The reaction vial was immediately vortexed then shaken reciprocally for $5 \mathrm{~min}$. The slurry was allowed to settle, and the aqueous portion was aspirated and discarded.

The alumina was washed once with Tris buffer/EDTA by adding 1 $\mathrm{ml}$ of the buffer, vortexing, and then aspirating the liquid portion after settling. The alumina was then washed with $1 \mathrm{ml}$ glass-distilled water, vortexed, and the liquid aspirated after settling. A 1-ml portion of distilled water was again added to the reaction vial, and then the contents were 
transferred to a microfilter assembly (part No. MF5500, Bioanalytical Systems, West Lafayette, IN) loaded with an RC-58 (Bioanalytical Systems) membrane. To dry the alumina, the microfilter was placed into a small centrifuge and spun at $1,000 \mathrm{~g}$ for $30 \mathrm{~s}$. The bottom, receiving portion of the microfilter, now full with filtrate, was exchanged with an empty receiver tube. A $200-\mu \mathrm{l}$ aliquot of $0.1 \mathrm{M} \mathrm{HClO}_{4}$ was added to the alumina in the top portion of the microfilter. The microfilter was vortexed briefly, and then let to stand for a 5-min period. The microfilter was again vortexed briefly, and then centrifuged at $1,000 \mathrm{~g}$ for $1 \mathrm{~min}$. The receiving portion of the microfilter contained the extracted catecholamines in $0.1 \mathrm{M} \mathrm{HClO}_{4}$. Catecholamine extracts were stored overnight at $-20^{\circ} \mathrm{C}$.

High-pressure liquid chromatography (HPLC; LC-304, Bioanalytical Systems) was utilized to separate $\left[{ }^{3} \mathrm{H}\right] \mathrm{NE}$ from $\left[{ }^{3} \mathrm{H}\right] \mathrm{EPI}$. The flow rate was $0.7 \mathrm{ml} / \mathrm{min}$. The mobile phase used to separate the catecholamines was $0.15 \mathrm{M}$ monochloroacetate buffer, $\mathrm{pH} 3.0$, containing $1.5 \mathrm{~g}$ $\mathrm{Na}_{2} \mathrm{EDTA}, 54 \mathrm{mg}$ sodium octyl sulfate, and $9.35 \mathrm{~g} \mathrm{NaOH}$ in 2 liters of glass-distilled, deionized water. The mobile phase was filtered and degassed before use. Catecholamine extracts obtained from the plasma samples were injected $(100 \mu l)$ into the HPLC system, and fractions were collected every $30 \mathrm{~s}$ from 6 min until $15.5 \mathrm{~min}$ after the injection.

A $200-\mu 1$ portion of each fraction was added to a scintillation vial containing $5 \mathrm{ml}$ scintillation fluid (ACS, New England Nuclear, Boston, MA). Samples were counted for $5 \mathrm{~min}$ in a scintillation counter (NuclearChicago Corp., Des Plaines, IL). A typical elution profile for both the venous and arterial samples is shown in Fig. 3.

Extraction ratios were determined during the stimulation period $(5$ $\mathrm{Hz}$ ) and control period. The counts under the peak corresponding to $\mathrm{NE}$ and EPI were summated. The extraction ratios for NE and EPI were calculated by the formula: Extraction ratio $=\mathrm{cpm}$ from arterial sample - cpm from venous sample/cpm from arterial sample.

The extraction ratios for NE and EPI during the control period were $0.488 \pm 0.046$ and $0.557 \pm 0.044$, respectively, and the extraction ratios for NE and EPI obtained during the stimulation period were $0.694 \pm 0.036$ and $0.735 \pm 0.030$, respectively. The NE and EPI extraction ratios obtained during either the control period or the $5-\mathrm{Hz}$ stimulation period were not significantly different (unpaired Student's $t$ test).

\section{Statistical analysis}

Two sample hypotheses were tested with either paired or unpaired Student's $t$ tests. Dose-response and frequency-response relationships during various treatments were compared using a fixed model two-way analysis of variance (ANOVA) in which one fixed factor was treatment (two or three levels) and the second fixed factor was frequency of nerve stimulation or dose of NE (three levels). Whenever three dose-response or frequency-response relationships were analyzed simultaneously, if the ANOVA revealed a significant treatment effect, the residual mean square from the ANOVA was applied in a Dunnett's test or Newman-Keuls

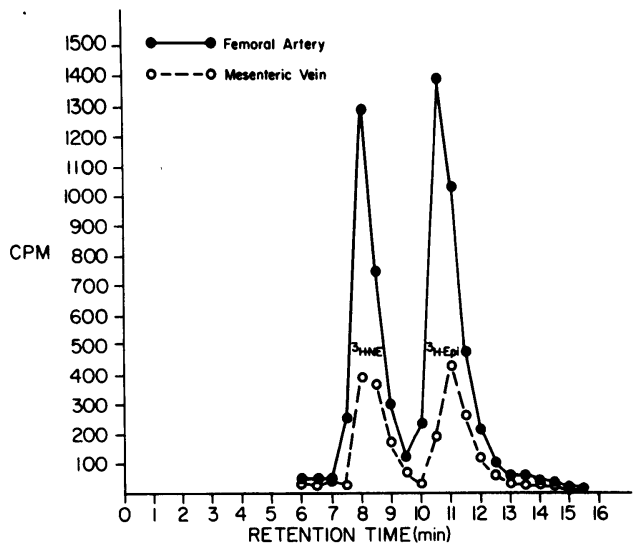

Figure 3. Typical chromatogram illustrating the extraction of $\left[{ }^{3} \mathrm{H}\right] \mathrm{NE}$ and $\left[{ }^{3} \mathrm{H}\right] \mathrm{EPI}$ across the rat mesentery. test to determine which treatments were different from control (Dunnett's test) or different from each other (Newman-Keuls test). All hypotheses tested were two-tailed and the criterion of significance was $P<0.05$. All statistical calculations were performed on a Digital Equipment Corporation 1099 computer (Maynard, MA) using the statistical package for the social sciences.

\section{Drugs and chemicals}

1-Norepinephrine bitartrate and pentobarbital were from Sigma Chemical Co. (St. Louis, MO) and 5-Ile-AII and 1-Sar-8-Ile-AII were from Peninsula Laboratories (San Carlos, CA).

\section{Results}

Systolic blood pressure and PRA in $2 K-1 C$ and sham-operated rats. Systolic blood pressure was determined by the tail cuff method 3 wk after surgery. As shown in Fig. 4, the systolic blood pressure in $2 \mathrm{~K}-1 \mathrm{C}$ animals $(173 \pm 7 \mathrm{mmHg} ; n=12)$ was significantly greater $(P<0.001$; unpaired Student's $t$ test) than the systolic blood pressure in the sham-operated animals $(129 \pm 3$ $\mathrm{mmHg} ; n=12$ ).

On the following day, these same rats were killed by decapitation and blood was collected and analyzed for PRA and AI levels (Fig. 4). PRA in $2 \mathrm{~K}-1 \mathrm{C}$ rats was $5.8 \pm 1.1 \mathrm{ng} \mathrm{AI} / \mathrm{ml}$ per $\mathrm{h}$, whereas PRA in sham-operated animals was $2.5 \pm 0.4 \mathrm{ng} \mathrm{AI} / \mathrm{ml}$ per h. Plasma AI levels in $2 \mathrm{~K}-1 \mathrm{C}$ rats and sham-operated rats were $478 \pm 74 \mathrm{pg} / \mathrm{ml}$ and $193 \pm 35 \mathrm{pg} / \mathrm{ml}$, respectively. PRA and plasma AI levels were significantly greater in $2 \mathrm{~K}-1 \mathrm{C}$ animals than in sham-operated animals $(P<0.001$; unpaired Student's $t$ test). These data indicated that in our hands the procedure of clipping one renal artery afforded a high renin model of renovascular hypertension.

Effects of AII or AII + 1-Sar-8-Ile-AII on vasoconstrictor responses to $P N S$ and $N E$ in normal rats. Mesenteric vascular responses to PNS in normal rats (N group) are shown in Fig. 5. Vascular responses were obtained in a control period, in the presence of AII ( $9 \mathrm{ng} / \mathrm{min})$ alone, and in the presence of both AII and 1-Sar-8-Ile-AII (150 ng/min).

The vascular response to PNS increased linearly over the
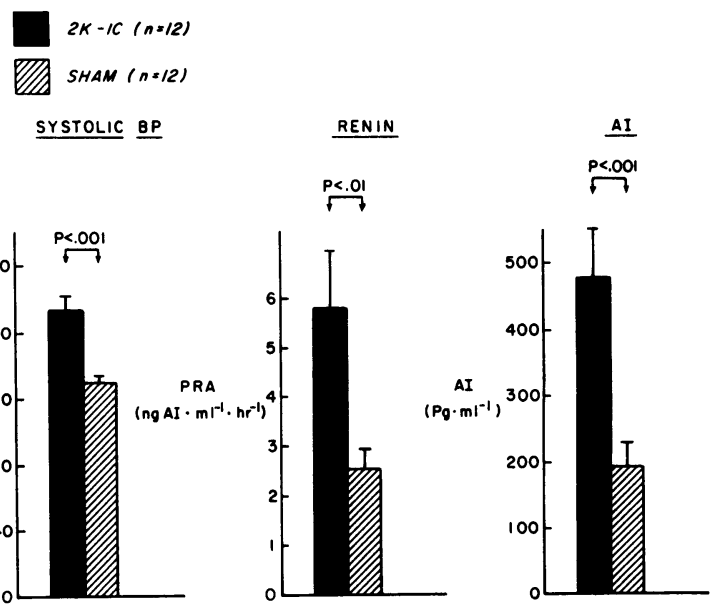

Figure 4. Systolic blood pressure, PRA, and plasma angiotensin I (AI) level in 2K-1C and sham-operated (Sham) rats. Data from each group are presented as mean \pm SEM. Student's $t$ test (two-tailed, unpaired) indicated that systolic blood pressure, PRA and plasma AI level were significantly greater in $2 \mathrm{~K}-1 \mathrm{C}$ rats compared with sham-operated animals. 


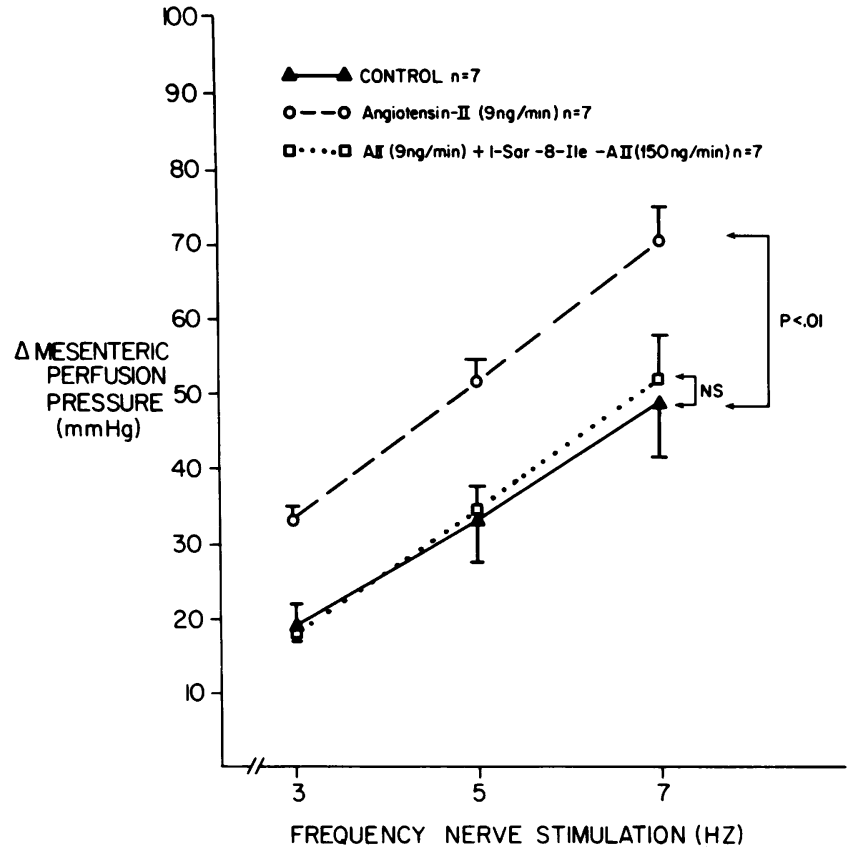

Figure 5. Vasoconstrictor responses to sympathetic nerve stimulation in normal rats before and during infusions of either angiotensin II (AII) or AII + 1-Sar-8-Ile-AII. Vasoconstrictor responses are presented as the mean change in perfusion pressure $\pm \mathrm{SEM}$. Vasoconstrictor responses in the control period were compared to vasoconstrictor responses in the AII-treated and the AII + 1-Sar-8-Ile-AII-treated periods by two-way ANOVA followed by a Dunnett's test. This analysis revealed that there was a significant enhancement of the vasoconstrictor responses during AII infusion, as compared to the vasoconstrictor responses during the control period $(P<0.01)$. There was not a statistically significant difference (NS) between responsiveness in the control period compared to the AII + 1-Sar-8-Ile-AII-treated period.

range of 3 to $7 \mathrm{~Hz}$. Responses to PNS in the presence of AII were significantly enhanced relative to control responses ( $P$ $<0.001$; two-way ANOVA). The angiotensin II antagonist, 1Sar-8-Ile-AII, reduced the enhanced mesenteric vascular responses to levels comparable to control responses. In fact, control responses and responses in the presence of AII plus 1-Sar-8-IleAII were not statistically different. These data indicated that the dose of 1-Sar-8-Ile-AII chosen totally blocked the effects of AII on responses to PNS.

The mesenteric vascular responses to NE in normal rats ( $\mathrm{N}$ group) in a control period, in the presence of AII $(9 \mathrm{ng} / \mathrm{min})$, and in the presence of AII plus 1-Sar-8-Ile-AII $(150 \mathrm{ng} / \mathrm{min})$ are shown in Fig. 6. The log dose response to NE increased linearly over the range of 100 to $300 \mathrm{ng} \mathrm{NE}$ in the control period. Responses to NE in the AII-treated period were significantly enhanced ( $P<0.01$; two-way ANOVA) relative to the control period. Although the AII antagonist reduced the AII enhancement of responses $(P<0.05$; two-way ANOVA), there remained a significant difference $(P<0.05$; two-way ANOVA) between the control and the AII plus 1-Sar-8-Ile-AII-treated periods. This contrasts with the total inhibition by 1-Sar-8-Ile-AII of the AII enhancement of responses to PNS. These data indicated that the dose of 1-Sar-8-Ile-AII used in this study at least partially blocked the effects of AII on exogenous NE.

The AII-induced enhancement of vascular responses to PNS was greater than the enhancement by AII of responses to NE.

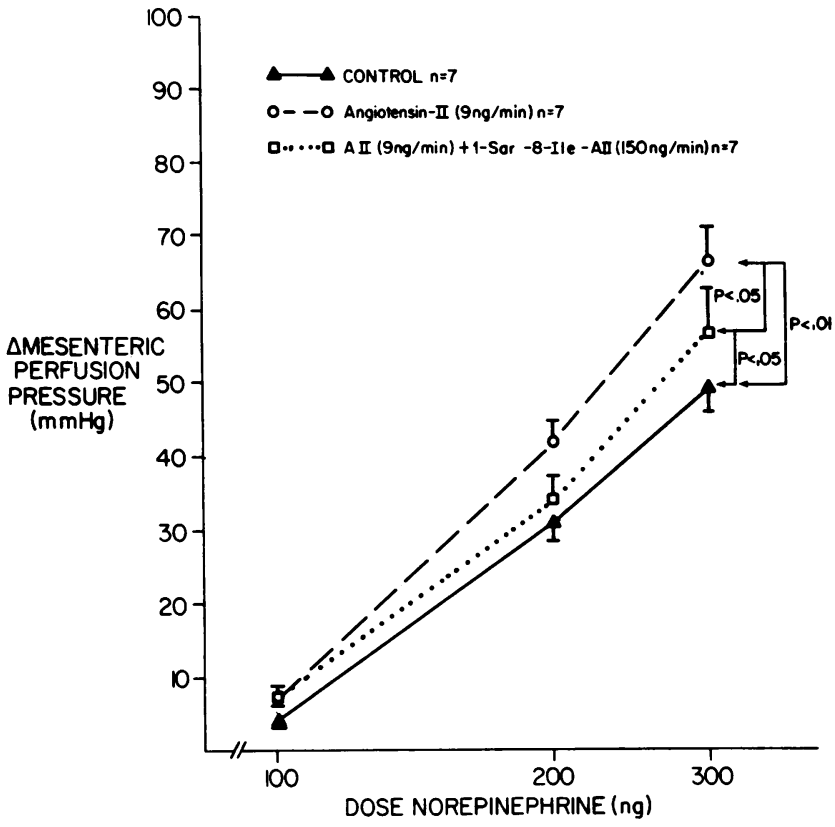

Figure 6. Vasoconstrictor responses to norepinephrine in normal rats before and during infusions of angiotensin II (AII) or AII + 1-Sar-8Ile-AII. Vasoconstrictor responses are presented as the mean change in perfusion pressure \pm SEM. Responses in the control, AII-treated, and AII + 1-Sar-8-Ile-AII-treated periods were analyzed by two-way ANOVA followed by Neuman-Keuls test. AII infusion significantly enhanced the vasoconstrictor responses to norepinephrine as compared to the vasoconstrictor responses during vehicle infusion $(P<0.01)$. AII + 1-Sar-8-Ile-AII infusion significantly decreased the vasoconstrictor responses, as compared to the vasoconstrictor responses during AII infusion alone $(P<0.05)$. The AII antagonist did not completely abolish the AII-induced enhancement of norepinephrine vasoconstrictor responses $(P<0.05)$.

To assess this differential enhancement of responses to PNS compared with the enhancement of responses to NE, the following analysis was performed. Linear regression analysis was computed on data from each individual rat, and the frequencies of PNS and doses of NE eliciting vascular responses of 20,30, and $40 \mathrm{mmHg}$ in the control frequency-response and NE doseresponse curves were calculated from the best-fit relationship. The vascular responses during treatment with AII corresponding to these calculated frequencies of PNS and doses of NE (from above) were determined by linear regression analysis of the frequency-response and NE dose-response curves obtained during the infusion of AII. The difference (delta) between the calculated vascular response during AII infusion and the control mesenteric response of either 20,30 , or $40 \mathrm{mmHg}$ was determined. A schematic representation of this analysis is shown in Fig. 7.

The differential enhancement by AII of the response to PNS compared to the response to NE is shown in Fig. 7. AII-induced potentiation of the response to PNS was greater than the potentiation of responses to NE at frequencies of PNS and doses of NE producing equivalent responses in the absence of AII ( $P$ $<0.001$; two-way ANOVA). These data are consistent with previously published results indicating that the primary interaction of exogenous AII with noradrenergic nerve terminals is prejunctional (see Discussion).

Effects of renal artery clipping on vasoconstrictor responses to PNS and NE. Mesenteric vascular responses to PNS in the 

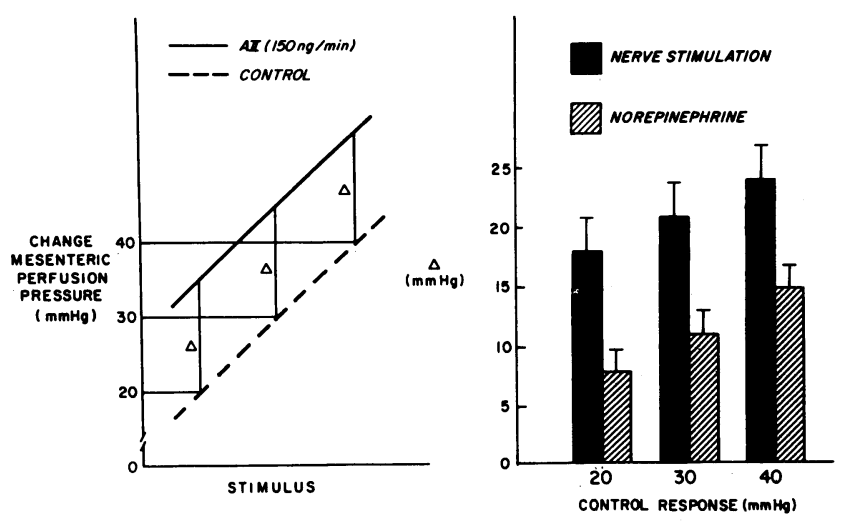

Figure 7. Analysis of angiotensin II(AII)-induced enhancement of noradrenergic vasoconstrictor responses in normal rats. The AII-induced enhancement (delta) of the mesenteric perfusion pressure response to either periarterial nerve stimulation (data shown in Fig. 5) or to injected norepinephrine (data shown in Fig. 6) was determined at frequencies of nerve stimulation and doses of norepinephrine causing equal responses in the control period of 20,30 , and $40 \mathrm{mmHg}$ (see text for details). The potentiation by AII of responses to nerve stimulation was significantly greater than the enhancement by AII of responses to equipressor doses of norepinephrine (two-way ANOVA; $P$ $<0.01$ ).

2K-1C group ( $n=11$ ) were compared with mesenteric vascular responses to PNS in the sham-operated group $(n=11)$. As shown in Fig. 8, responses to PNS increased linearly over the frequency range of 3 to $7 \mathrm{~Hz}$ in both the $2 \mathrm{~K}-1 \mathrm{C}$ and sham-operated groups. However, the response to PNS in the $2 \mathrm{~K}-1 \mathrm{C}$ group was much greater than the response to PNS in the sham-operated group $(P<0.001$; two-way ANOVA).

Responses to NE also were compared between the $2 \mathrm{~K}-1 \mathrm{C}$ and sham-operated groups (Fig. 9). The log dose-response to NE increased linearly in the range of 100 to $300 \mathrm{ng}$ in both the $2 \mathrm{~K}$ -

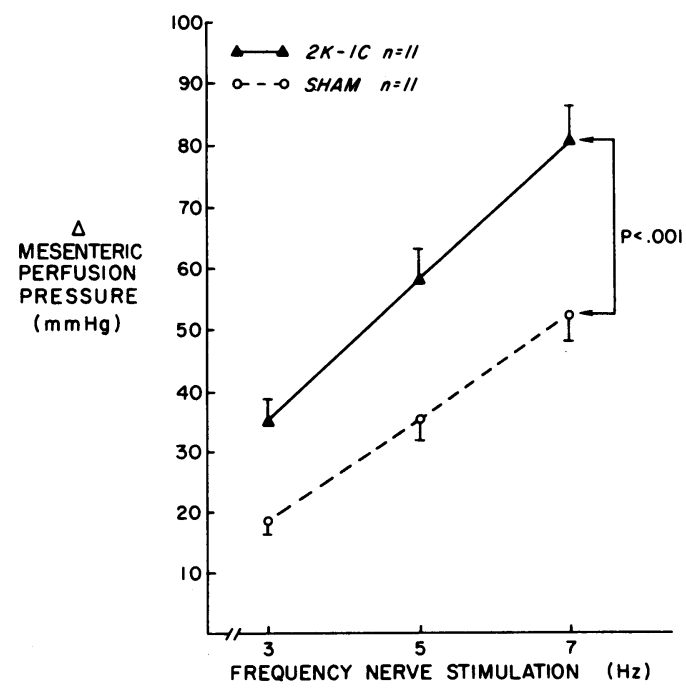

Figure 8. Vasoconstrictor responses to periarterial nerve stimulation in 2K-1C and sham-operated rats (Sham) 3 wk following renal artery clipping or sham operation. Two-way ANOVA indicated that renal artery clipping significantly enhanced responses to periarterial nerve stimulation in $2 \mathrm{~K}-1 \mathrm{C}$ rats compared with responses in sham-operated rats $(P<0.001)$. Vasoconstrictor responses are presented as the mean change in perfusion pressure $\pm \mathbf{S E M}$.

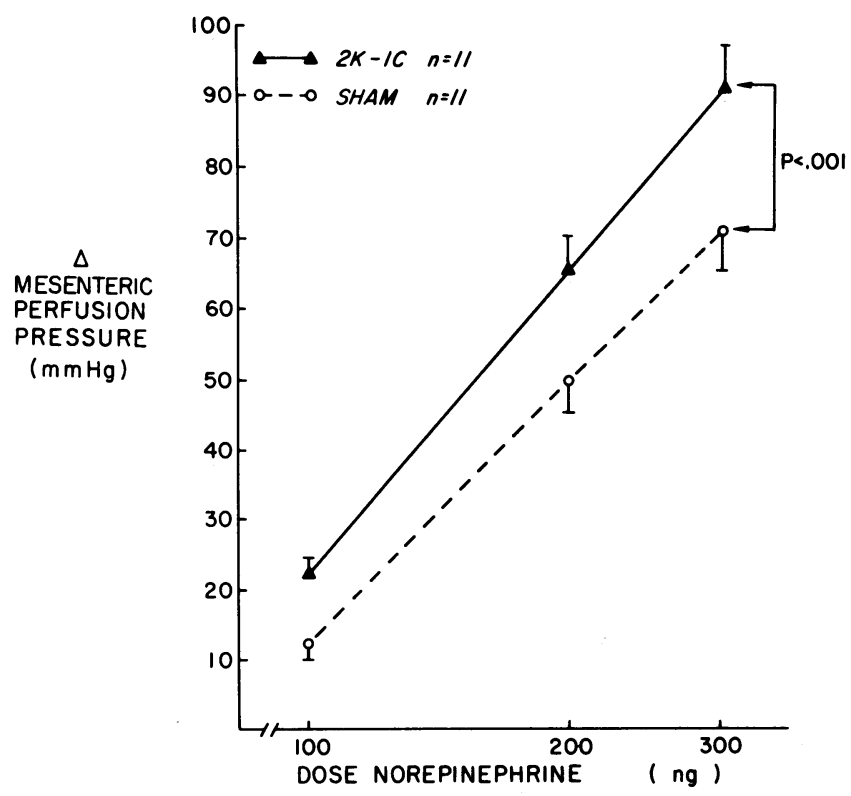

Figure 9. Vasoconstrictor responses to norepinephrine in $2 \mathrm{~K}-1 \mathrm{C}$ and sham-operated (Sham) rats 3 wk after renal artery clipping or sham operation. Vasoconstrictor responses are presented as the mean change in perfusion pressure \pm SEM. Two-way ANOVA indicated that renal artery clipping significantly enhanced responses to norepinephrine in $2 \mathrm{~K}-1 \mathrm{C}$ rats as compared to responses in sham-operated rats $(P$ $<0.001)$.

$1 \mathrm{C}$ and sham-operated animals. However, responses to NE in the $2 \mathrm{~K}-1 \mathrm{C}$ group were greater than responses to NE in shamoperated rats $(P<0.001$; two-way ANOVA).

These data demonstrated that vascular responses to PNS and exogenous NE were elevated in $2 \mathrm{~K}-1 \mathrm{C}$ animals relative to sham-operated animals. Further, the enhancement of vascular responses in 2K-1C rats compared with sham-operated rats appeared greater for responses to PNS than for responses to NE. To quantitate this differential enhancement by renal artery clipping of vascular responses to PNS and NE, an analysis was performed similar to that described above for the AII infusion experiments. In this analysis, a linear regression was performed on the frequency-response curve and NE dose-response curve obtained by combining all the data from the sham-operated animals. From these two regression equations, the frequencies of PNS and doses of NE required to provoke responses of 20, 30, and $40 \mathrm{mmHg}$ in sham-operated animals were calculated. Next, linear regressions of the frequency-response curves and NE doseresponse curves for each individual rat in the $2 \mathrm{~K}-1 \mathrm{C}$ group were performed, and the vascular responses to the previously calculated frequencies and doses of NE were computed. The differences between the calculated vascular responses to PNS and NE in $2 \mathrm{~K}-1 \mathrm{C}$ animals and 20,30 , and $40 \mathrm{mmHg}$ were calculated. A schematic representation of this analysis is illustrated in Fig. 10. This analysis indicated that renal artery clipping enhanced vascular responses to frequencies of PNS, which in sham-operated animals elicited responses of 20,30 , or $40 \mathrm{mmHg}$, more than to doses of NE, which in sham-operated animals elicited responses of 20,30 , and $40 \mathrm{mmHg}(P<0.01$; two-way ANOVA). This analysis suggested that, like exogenous AII, the effects of renal artery clipping on noradrenergic neurotransmission were primarily prejunctional. Further, a comparison of Figs. 7 and 

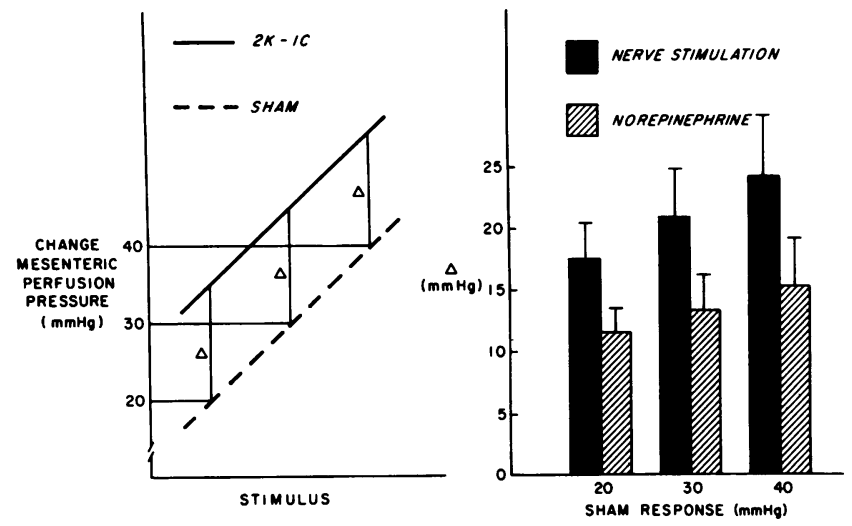

Figure 10. Analysis of clipping-induced enhancement of noradrenergic vasoconstrictor responses. The renal artery clipping-induced enhancement (delta) of the mesenteric perfusion pressure response to periarterial nerve stimulation (data shown in Fig. 8) and to norepinephrine (data shown in Fig. 9) was determined at frequencies of nerve stimulation and doses of norepinephrine causing equal responses in sham-operated rats of 20,30 , and $40 \mathrm{mmHg}$ (see text for details). The potentiation by renal artery clipping of responses to nerve stimulation was significantly greater than the enhancement of responses to equipressor doses of norepinephrine (two-way ANOVA; $P<0.01$ ).

10 suggested a striking similarity between the effects of exogenous AII and renal artery clipping on responses to PNS and NE.

Effects of 1-Sar-8-Ile-AII on vasoconstrictor responses to PNS and $N E$ in $2 K-1 C$ rats. Vascular responses to PNS in the $2 \mathrm{~K}$ $1 \mathrm{C}$ group during a control period $(n=11)$ and during infusion of either saline $(n=5)$ or 1 -Sar-8-Ile-AII $(150 \mathrm{ng} / \mathrm{min} ; n=6)$ are depicted in Fig. 11. Control responses to PNS, responses to PNS in the presence of 1-Sar-8-Ile-AII, and responses to PNS during vehicle infusion all increased linearly over the frequency range of 3 to $7 \mathrm{~Hz}$. No statistically significant differences were observed between control responses and responses to PNS in the presence of vehicle. However, there was a significant decrease $(P<0.01$; two-way ANOVA) in responses to PNS in the presence of 1-Sar-8-Ile-AII when compared with control responses. These data indicated that in the presence of an AII antagonist, responses to sympathetic nerve stimulation were significantly decreased in $2 \mathrm{~K}-1 \mathrm{C}$ animals. The observed decrease in responses to PNS was not due to time dependent changes in the preparation since responses in the presence of vehicle were not statistically different from control responses.

Dose-responses to $\mathrm{NE}$ in the $2 \mathrm{~K}-1 \mathrm{C}$ group during a control period $(n=11)$ and during infusions of either saline $(n=5)$ or 1-Sar-8-Ile-AII (150 ng/min; $n=6)$ are illustrated in Fig. 12. Log dose-responses to NE increased linearly over the range of 100 to $300 \mathrm{ng} \mathrm{NE}$ in the control period and in the presence of either 1-Sar-8-Ile-AII or vehicle. No statistically significant differences were obtained among dose-responses to NE in the control period, the 1-Sar-8-Ile-AII-treated period, or the vehicletreated period. These data demonstrated that dose-responses to NE were unaffected by the AII receptor antagonist, 1-Sar-8-IleAII, at least during the time frame of these experiments.

Effects of 1-Sar-8-Ile-AII on vasoconstrictor responses to PNS and NE in sham-operated rats. Control responses to PNS ( $n$ $=11$ ), responses to PNS in the presence of 1-Sar-8-Ile-AII (150 $\mathrm{ng} / \mathrm{min} ; n=6$ ), and responses to PNS in the presence of vehicle $(n=5)$ all increased linearly over the range of 3 to $7 \mathrm{~Hz}$ in sham-

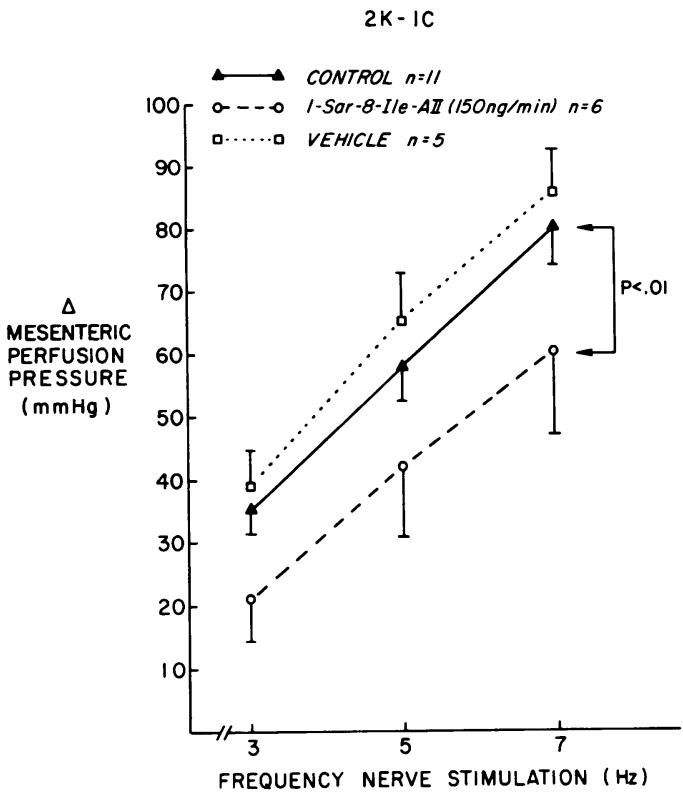

Figure 11. Vasoconstrictor responses to periarterial nerve stimulation in $2 \mathrm{~K}-1 \mathrm{C}$ rats treated with either 1-Sar-8-Ile-AII or vehicle (saline). Mesenteric perfusion pressure responses to periarterial nerve stimulation were determined in $2 \mathrm{~K}-1 \mathrm{C}$ rats during a control period and during an infusion of either 1-Sar-8-lle-AII or vehicle. Vasoconstrictor responses are presented as the mean change in perfusion pressure \pm SEM Control vasoconstrictor responses were compared to vasoconstrictor responses in the presence of 1-Sar-8-Ile-AII and to vasoconstrictor responses in the presence of vehicle by two-way ANOVA followed by a Dunnett's test. This analysis revealed that there was a significant decrease $(P<0.01)$ in the vasoconstrictor response to nerve stimulation in the presence of 1-Sar-8-Ile-AII as compared with the control response. No statistically significant differences were observed between control responses and responses in the presence of vehicle.

operated rats (Fig. 13). No statistically significant differences were observed among the control, the 1-Sar-8-Ile-AII-treated, and the vehicle-treated periods, although a trend towards smaller responses after treatment with 1-Sar-8-Ile-AII was noted. These data indicated that the inhibition of responses to PNS by 1-Sar8-Ile-AII was selective for renovascular hypertensive rats and occurred to a lesser extent in sham-operated animals.

Dose responses to NE in sham-operated rats are shown in Fig. 14. Log dose responses to NE increased linearly over the range of 100 to $300 \mathrm{ng} \mathrm{NE}$ in the control period $(n=11)$ and in the presence of either 1-Sar-8-Ile-AII $(150 \mathrm{ng} / \mathrm{min} ; n=6)$ or vehicle $(n=5)$. Again, no statistically significant differences were observed among the control, the 1-Sar-8-Ile-AII-treated, and the vehicle-treated periods (two-way ANOVA).

Baseline perfusion pressure and mean arterial blood pressure. Baseline perfusion pressures and mean arterial blood pressures immediately before eliciting vascular responses during each period for each group of animals are detailed in Tables II and III, respectively. As shown, no treatment significantly altered baseline perfusion pressure or arterial blood pressure compared with the control period, with the exception that exogenous AII increased perfusion pressure $\sim 30 \%$.

Effect of 1-Sar-8-Ile-AII on neuronal NE spillover in $2 K-1 C$ and sham-operated rats. As shown in Fig. 15, in vehicle treated $2 \mathrm{~K}-1 \mathrm{C}$ rats sympathetic nerve stimulation increased the neuronal spillover of NE (calculated by Eq. 3) approximately fivefold ( $P$ 


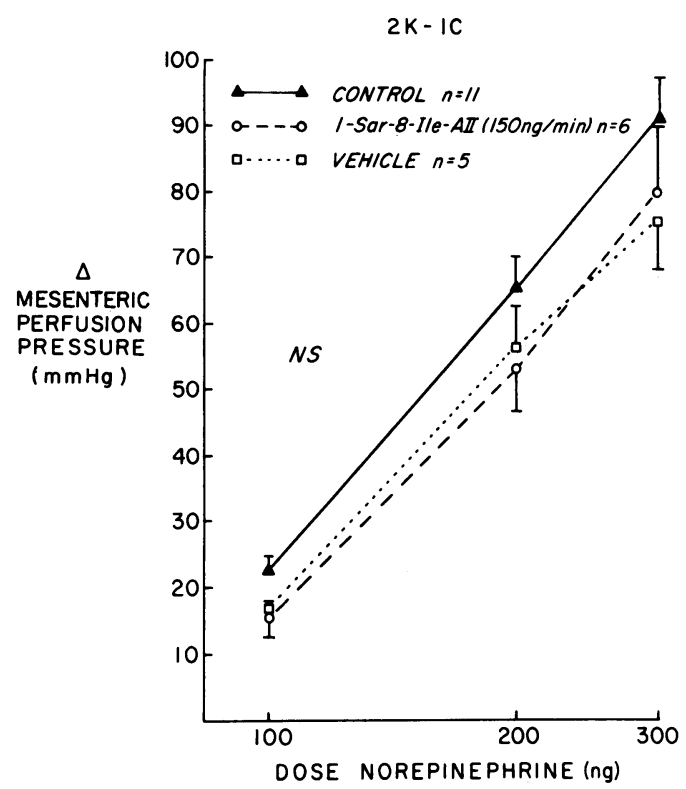

Figure 12. Vasoconstrictor responses to norepinephrine in $2 \mathrm{~K}-1 \mathrm{C}$ rats treated with either 1-Sar-8-Ile-AII or vehicle (saline). Mesenteric perfusion pressure responses to injections of norepinephrine were determined in $2 \mathrm{~K}-1 \mathrm{C}$ rats during a control period and during an infusion of either 1-Sar-8-Ile-AII or vehicle. Vasoconstrictor responses are presented as the mean change in perfusion pressure \pm SEM. Control vasoconstrictor responses were compared to vasoconstrictor responses in the presence of 1-Sar-8-Ile-AII and to vasoconstrictor responses in the presence of vehicle by two-way ANOVA. This analysis indicated that there were no statistically significant differences in vascular responsiveness to NE among the control, the 1-Sar-8-Ile-AII-treated, and the vehicle-treated periods.

$<0.004$; paired Student's $t$ test). In contrast in $2 \mathrm{~K}-1 \mathrm{C}$ rats receiving an intramesenteric artery infusion of 1-Sar-8-Ile-AII (300 $\mathrm{ng} / \mathrm{min}$ ), sympathetic nerve stimulation only slightly and nonsignificantly increased NE spillover. Further, the level of NE spillover during nerve stimulation in the 1-Sar-8-Ile-AII-treated group was significantly lower than in the group receiving vehicle $(P<0.05$; unpaired Student's $t$ test). Fig. 16 illustrates the effects of 1-Sar-8-Ile-AII on NE spillover in sham-operated rats. In these normotensive rats, nerve stimulation significantly increased NE spillover to the same extent in vehicle-treated and 1-Sar-8-IleAII-treated animals. These data indicated that antagonism of AII receptors reduced the neuronal release of NE in renovascular hypertensive animals, but not in normotensive animals.

For comparison, other methods for assessing NE spillover are presented in Figs. 17 (2K-1C rats) and 18 (sham-operated rats), including: (a) NE spillover calculated according to Eqs. 1 and 2: (b) the plasma arteriovenous concentration difference for $\mathrm{NE}$; and $(c)$ the venous plasma concentration of NE. In shamoperated animals NE release appeared to increase equally in vehicle and 1-Sar-8-Ile-AII treated animals, regardless of which method was used to estimate NE release. In $2 \mathrm{~K}-1 \mathrm{C}$ rats, 1-Sar8-Ile-AII appeared to reduce NE release regardless of which method was used to estimate NE release. However, none of the four techniques presented in Fig. 17 afforded a statistically significant difference in NE release between control and treated animals during nerve stimulation. For reasons discussed in the methods, we think that the NE spillover calculated according

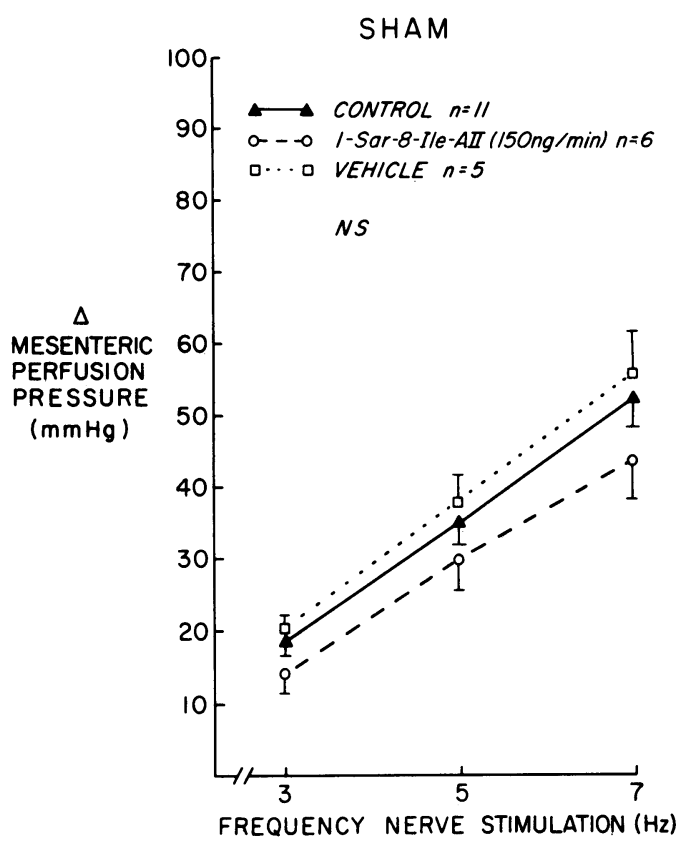

Figure 13. Vasoconstrictor responses to periarterial nerve stimulation in sham-operated (Sham) rats treated with either 1-Sar-8-Ile-AII or vehicle (saline). Mesenteric perfusion pressure responses to periarterial nerve stimulation were determined in sham-operated rats during a control period and during an infusion of either 1-Sar-8-Ile-AII or vehicle (saline). Vasoconstrictor responses are presented as the mean change in perfusion pressure \pm SEM. Control vasoconstrictor responses were compared to vasoconstrictor responses in the presence of 1-Sar8-Ile-AII and to vasoconstrictor responses in the presence of vehicle by two-way ANOVA. No statistically significant differences in vascular responsiveness to nerve stimulation among the control, the 1-Sar-8Ile-AII-treated, and the vehicle-treated periods were detected.

to Eq. 3 (Figs. 15 and 16) provides the most valid basis for interpretation.

\section{Discussion}

Although it is well known that exogenous AII can enhance noradrenergic neurotransmission, both in vitro and in vivo, the significance of AII-noradrenergic interactions in vivo in renovascular hypertension has, until now, remained unclear. A priori, there are at least two mechanisms that, despite positive results with exogenous AII, would render AII-noradrenergic interactions in chronic renovascular hypertension unimportant. First, AII levels at the sympathetic neuroeffector junction may not be sufficiently high in renovascular hypertension to activate junctional AII receptors. Second, even if junctional levels of AII are adequate to enhance noradrenergic neurotransmission acutely, it is possible that in the long term a tolerance to the facilitatory effects of AII on noradrenergic neurotransmission develops. Therefore, in our view, the hypothesis that increased levels of endogenous AII facilitate noradrenergic neurotransmission in chronic renovascular hypertension was in need of more stringent testing.

The purpose of the studies described in this report was to critically evaluate the hypothesis that in renovascular hypertension sympathetic neurotransmission is enhanced because of the facilitatory effects of AII on the noradrenergic neuroeffector junction. To test this hypothesis, two strategies were employed. 


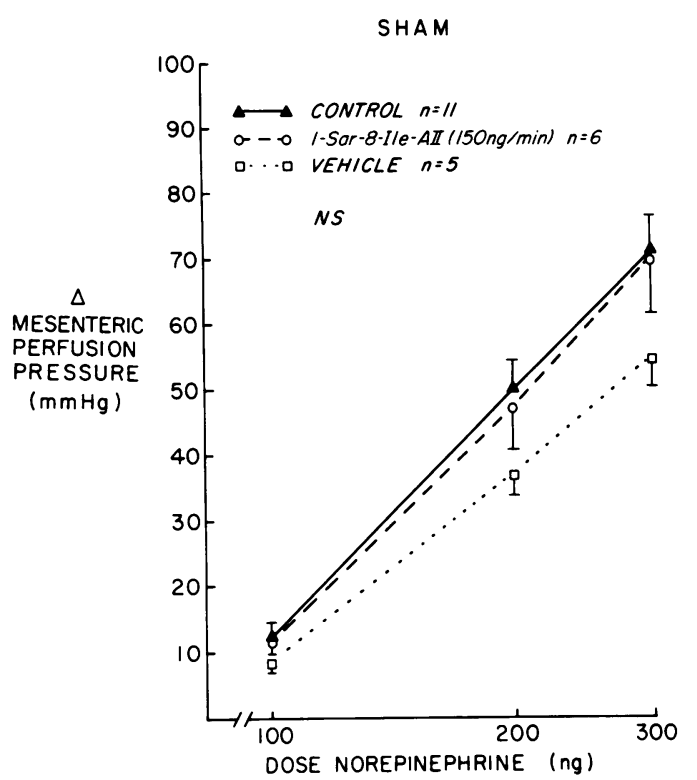

Figure 14. Vasoconstrictor responses to NE in sham-operated (Sham) rats treated with either 1-Sar-8-Ile-AII or vehicle (saline). Mesenteric perfusion pressure responses to injections of NE were determined in sham-operated rats during a control period and during an infusion of either 1-Sar-8-Ile-AII or vehicle. The vasoconstrictor responses are presented as the mean change in perfusion pressure \pm SEM. Control vasoconstrictor responses were compared to responses in the presence of 1Sar-8-Ile-AII and vehicle by two-way ANOVA. No statistically signifcant differences in vascular responsiveness to NE among the control, the 1-Sar-8-Ile-AII-treated, and the vehicle-treated periods were detected.

First, the effects of chronic renal artery clipping and exogenous AII on mesenteric vascular responses to sympathetic nerve stimulation were compared. If increased levels of endogenous AII facilitate neurotransmission in renovascular hypertensive rats, then vascular responses to sympathetic nerve stimulation should be increased by induction of renovascular hypertension, and this effect should be mimicked by exogenous AII. This prediction was confirmed. Second, if AII-noradrenergic interactions are responsible for enhancing neurotransmission in renovascular hypertension, then antagonism of AII receptors should reduce the vascular response to sympathetic nerve stimulation in $2 \mathrm{~K}-1 \mathrm{C}$ rats, whereas in sham-operated animals AII receptor antagonism should have a lesser or no effect (depending on the significance of AII-noradrenergic interactions in normotensive animals). This prediction also was corroborated. Our results indicate, therefore, that chronic renal artery stenosis enhances sympathetic neurotransmission, and that this enhancement is mediated in part by an AII-dependent mechanism.

Our conclusion that elevated levels of endogenous AII do facilitate noradrenergic neurotransmission in renovascular hypertension raises two additional questions: How does endogenous AII enhance neurotransmission in renovascular hypertension? Is neurotransmission enhanced in renovascular hypertension by circulating AII or locally formed AII or both?

Previous studies indicate that exogenous AII can influence neurotransmission at the noradrenergic neuroeffector junction in three ways: (a) enhancement of release of NE from the nerve terminal (i.e., for any given frequency of nerve stimulation more $\mathrm{NE}$ is released), (b) inhibition of neuronal uptake of NE, and (c) enhanced responsiveness of the effector organ to released NE (i.e., for any given level of $\mathrm{NE}$ in the junctional cleft a greater response is elicited).

That exogenous AII enhances NE release has been well documented. In canine hindquarters the vascular response to exogenous AII was markedly attenuated by sympathectomy (25). In contrast, vascular responses to injected NE were unchanged by sympathectomy. Further, in a number of studies, AII was found to augment vascular responses to electrical stimulation of sympathetic nerves, without altering vascular responses to exogenous NE (31-33). In addition, AII was observed to increase nerve stimulation-induced release of $\mathrm{NE}$ from isolated perfused tissues, even when changes in NE reuptake were prevented (20, $34,35)$. Finally, AII was shown to enhance the release of dopamine-beta-hydroxylase from electrically stimulated rabbit left atrium (36). Since dopamine-beta-hydroxylase is an enzyme released from noradrenergic nerve terminals during exocytosis of NE containing vesicles, enhancement of its release most likely indicates an increase in the exocytosis of NE. Taken as a whole, previously published data clearly indicate that exogenous AII can facilitate NE release.

Although AII facilitates the release of neurotransmitter at most noradrenergic neuroeffector junctions, the effects of this peptide on NE uptake and vascular sensitivity to NE are less clear. If AII influences the uptake of NE or the postjunctional response to NE, an increase in the vascular response to exogenous NE would be anticipated. However, in many cases AII was shown not to affect the vascular response to exogenous NE (31-33). Therefore, at some neuroeffector junctions AII does not alter

Table II. Baseline Perfusion Pressure ( $\mathrm{mmHg}$ ) Immediately before Eliciting Vascular Responses during the Control, Vehicle (Saline)Treated, Angiotensin II (AII)-Treated, 1-Sar-8-Ile-AII-Treated, and AII + 1-Sar-8-Ile-AII-Treated Periods

\begin{tabular}{llllll}
\hline & \multicolumn{1}{c}{ Treatment } & & & \\
\cline { 2 - 6 } Group & Control & Vehicle & AII & 1-Sar-8-Ile-AII & AII + 1-Sar-8-Ile-AII \\
\hline $\begin{array}{l}\text { Normals (7) } \\
\text { 2K-1C (11) }\end{array}$ & $53 \pm 2$ & - & $70 \pm 5^{*}$ & - & $50 \pm 3$ \\
Vehicle (5) & $73 \pm 3$ & $72 \pm 3$ & - & - & - \\
1-Sar-8-Ile-AII (6) & $63 \pm 4$ & - & - & $57 \pm 3$ & - \\
Sham-operated (11) & $61 \pm 4$ & $58 \pm 2$ & - & - & - \\
$\quad$ Vehicle (5) & $59 \pm 2$ & - & - & $55 \pm 2$ & - \\
1-Sar-8-Ile-AII (6) & & & & & \\
\end{tabular}

Values indicate mean \pm SEM. ${ }^{*} P<0.01$; paired Student's $t$ test. 
Table III. Mean Arterial Blood Pressure ( $\mathrm{mmHg}$ Immediately before Eliciting Vascular Responses during the Control, Vehicle (Saline)Treated, Angiotensin II (AII)-Treated, 1-Sar-8-Ile-AII-Treated, and AII + 1-Sar-8-Ile-AII-Treated Periods

\begin{tabular}{|c|c|c|c|c|c|}
\hline \multirow[b]{2}{*}{ Group } & \multicolumn{5}{|c|}{ Treatment } \\
\hline & Control & Vehicle & AlI & 1-Sar-8-Ile-AII & AII + 1-Sar-8-Ile-AIl \\
\hline Normals (7) & $105 \pm 3$ & - & $103 \pm 4$ & - & $104 \pm 5$ \\
\hline \multicolumn{6}{|l|}{$2 \mathrm{~K}-1 \mathrm{C}(11)$} \\
\hline Vehicle (5) & $115 \pm 5$ & $113 \pm 8$ & - & - & - \\
\hline 1-Sar-8-Ile-AII (6) & $128 \pm 6$ & - & - & $112 \pm 12$ & - \\
\hline \multicolumn{6}{|l|}{ Sham-operated (11) } \\
\hline Vehicle (5) & $101 \pm 6$ & $104 \pm 5$ & - & - & - \\
\hline 1-Sar-8-Ile-AII (6) & $106 \pm 6$ & - & - & $102 \pm 5$ & - \\
\hline
\end{tabular}

Values indicate mean \pm SEM. No treatment altered mean arterial blood pressure (paired Student's $t$ test).

either NE uptake or postjunctional responses to NE. On the other hand, AII was shown to potentiate the vascular response to $\mathrm{NE}$ in a number of other studies $(19,37-39)$. Enhancement of NE responses by AII could have been due to blockade of NE uptake and/or to an increase in the postjunctional sensitivity to NE. Evidence exists indicating that both mechanisms may be important $(23,40)$.

In our study, chronic renal artery clipping enhanced vascular responses to both sympathetic nerve stimulation and exogenous NE. However, renovascular hypertension enhanced vascular responses to sympathetic nerve stimulation to a greater extent than responses to NE. This observation supports the hypothesis that the release of NE from sympathetic nerve terminals is ac-

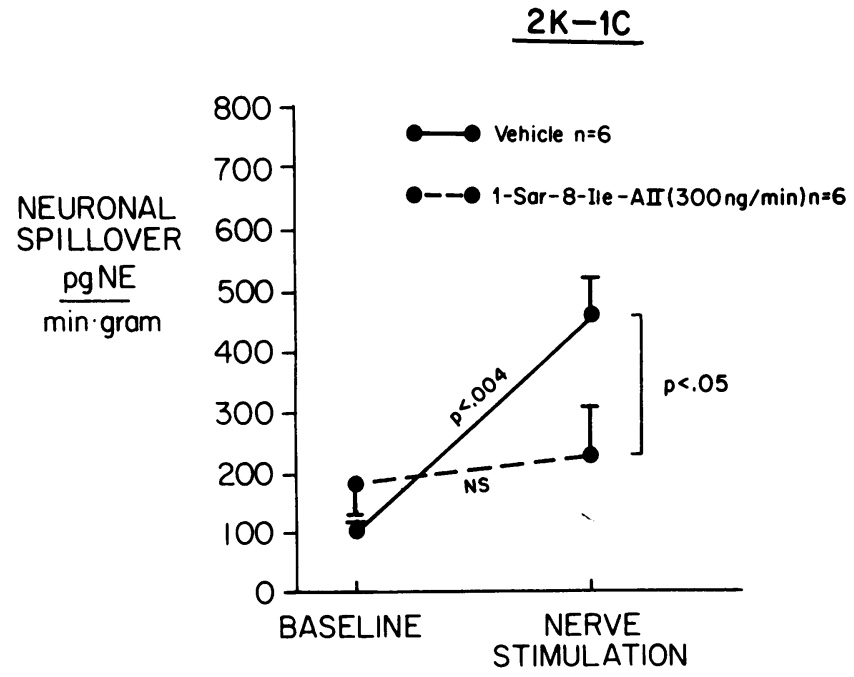

Figure 15. Mesenteric neuronal spillover in 2K-1C rats treated with either 1-Sar-8-Ile-AII or vehicle (saline). Mesenteric neuronal spillover was determined in vehicle-treated and 1-Sar-8-Ile-AII-treated rats during a baseline period (no stimulation) and during a stimulation period $(5 \mathrm{~Hz})$. Neuronal spillover is presented as the mean spillover \pm SEM. No statistically significant difference was observed in neuronal spillover between vehicle-treated and 1-Sar-8-Ile-AII-treated rats during the baseline period (unpaired Student's $t$ test). Periarterial nerve stimulation caused a significant $(P<0.004$; paired Student's $t$ test) elevation of neuronal spillover in vehicle-treated rats, but not in 1-Sar-8-IleAII-treated animals. The neuronal spillover during nerve stimulation was significantly greater $(P<0.05$; unpaired Student's $t$ test $)$ in rats treated with vehicle compared to rats treated with 1-Sar-8-Ile-AII. centuated by renovascular hypertension. Also, the AII-receptor antagonist, 1-Sar-8-Ile-AII, attenuated vascular responses to nerve stimulation, but not to NE, in renovascular hypertensive rats. This observation also supports the conclusion that AII facilitates NE release in renovascular hypertensive rats.

To further test the hypothesis that endogenous AII facilitates $\mathrm{NE}$ release in renovascular hypertensive rats we developed a technique for estimating the quantity of NE that is released from mesenteric sympathetic nerve terminals and escapes into the mesenteric vein. We designate this estimate of NE release "neuronal spillover" of NE. Athough the neuronal spillover of NE cannot be equated with the neuronal release of $\mathrm{NE}$, a change in the neuronal spillover of NE should reflect a change in the neu-

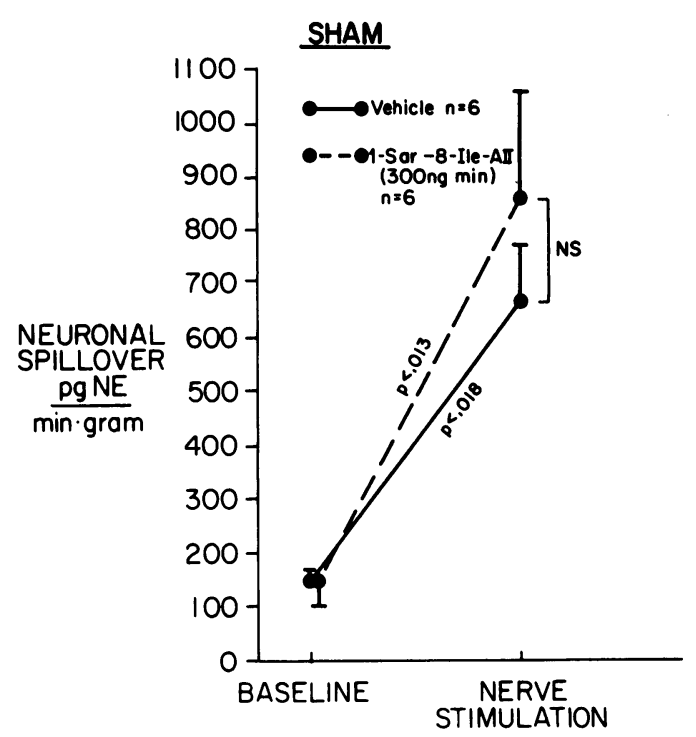

Figure 16. Mesenteric neuronal spillover in sham-operated (Sham) rats treated with either 1-Sar-8-Ile-AII or vehicle (saline). Mesenteric neuronal spillover was determined in vehicle-treated and 1-Sar-8-IleAII-treated sham-operated rats during a baseline (no stimulation) period and nerve stimulation period $(5 \mathrm{~Hz})$. Neuronal spillover is presented as the mean spillover \pm SEM. Mesenteric neuronal spillover increased during nerve stimulation in both the vehicle-treated and 1-Sar8-Ile-AII-treated rats (paired Student's $t$ test; $P<0.18$ and $P<0.013$, respectively). Unpaired Student's $t$ test did not reveal a statistically significant difference in baseline values or values during nerve stimulation in vehicle treated versus 1-Sar-8-Ile-AII-treated rats. 


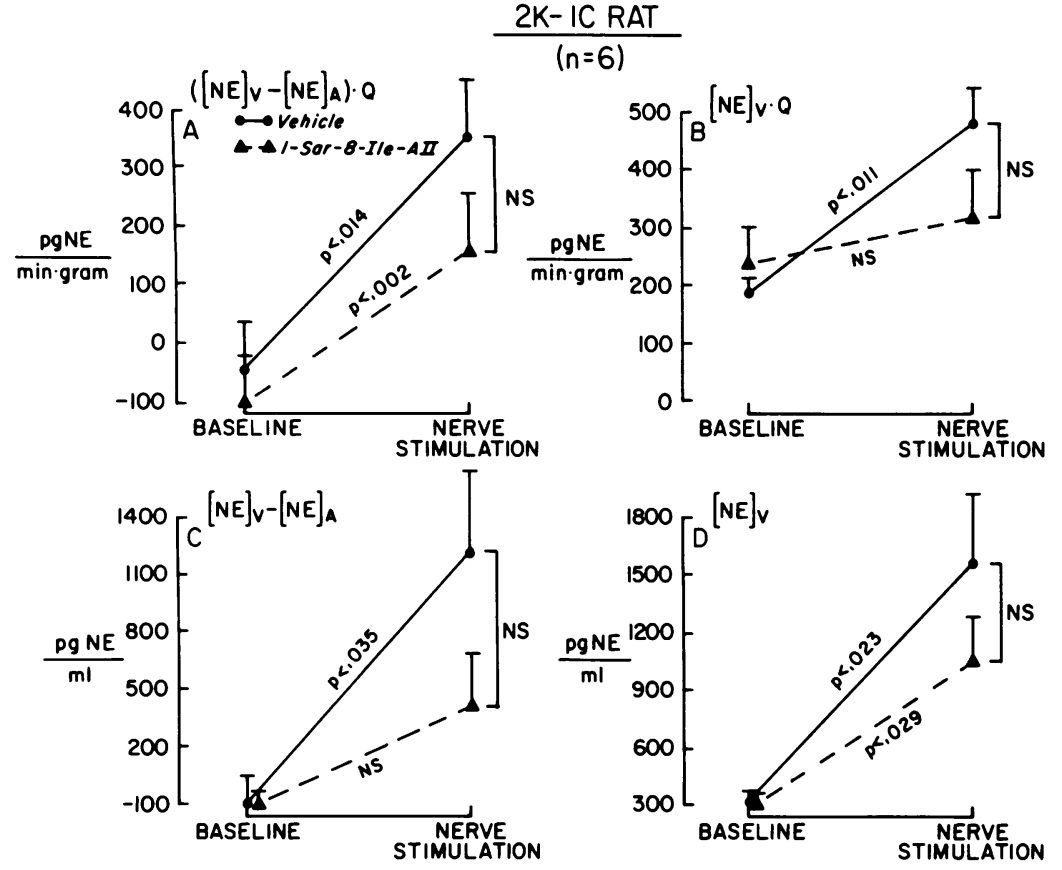

Figure 17. Summary of several indices of NE release in $2 \mathrm{~K}-1 \mathrm{C}$ rats treated with either 1-Sar-8-Ile-AII or vehicle (saline) under baseline conditions and during sympathetic nerve stimulation $(5 \mathrm{~Hz})$. Values indicate mean \pm SEM. Statistical values are from paired and unpaired Student's $t$ tests. $\mathrm{NE}_{\mathrm{v}}$, concentration of NE in mesenteric vein; $\mathrm{NE}_{\mathrm{a}}$, concentration of $\mathrm{NE}$ in aorta; $\mathrm{Q}$, mesenteric plasma flow. ronal release of $\mathrm{NE}$, given a constant efficiency of NE uptake and metabolism. The unique feature of our method for estimating the neuronal spillover of $\mathrm{NE}$ is that it corrects for the amount of NE entering the tissue in the arterial blood. As explained above (Methods section), other techniques for estimating the neuronal spillover of NE may either overestimate or underestimate the contribution of arterial NE to venous NE.

Using this new method to calculate the neuronal spillover of NE, we found that antagonism of AII receptors attenuated the increase in NE neuronal spillover induced by sympathetic nerve stimulation in $2 \mathrm{~K}-1 \mathrm{C}$ rats, but not in sham-operated rats. The attenuation of NE neuronal spillover by 1-Sar-8-Ile-AII in $2 \mathrm{~K}-1 \mathrm{C}$ rats could have been due to changes in NE metabolism or uptake. However, if this were the case, then 1-Sar-8-Ile-AII also would have altered the vascular response to exogenous NE in renovascular hypertensive animals. Since 1-Sar-8-Ile-AII did not alter the vascular response to $\mathrm{NE}$ in $2 \mathrm{~K}-1 \mathrm{C}$ rats, we conclude that the reduction in NE neuronal spillover by 1-Sar-8-Ile-AII was not due to changes in NE metabolism or uptake. Most likely the reduction in NE neuronal spillover by 1-Sar-8-Ile-AII was due specifically to attenuation of NE neuronal release. This conclusion corroborates our inferences from the vascular response studies and strengthens our contention that endogenous AII facilitates neurotransmission in renovascular hypertensive rats in part by enhancing NE release.

An apparent contradiction to our conclusion that endogenous AII facilitates NE release in $2 \mathrm{~K}-1 \mathrm{C}$ rats is the observation that nerve stimulation-induced NE neuronal spillover was not

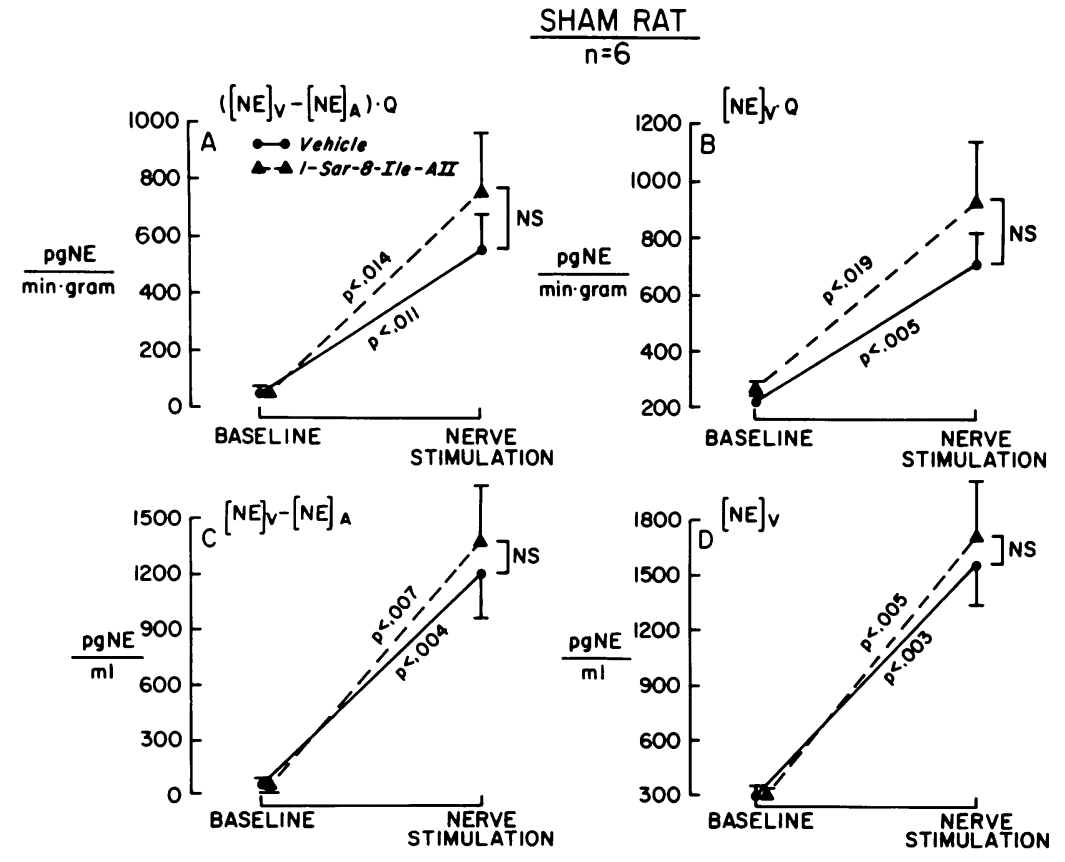

Figure 18. Summary of several indices of NE release in sham-operated (Sham) rats treated with either 1Sar-8-Ile-AII or vehicle (saline) under baseline conditions and during sympathetic nerve stimulation (5 $\mathrm{Hz}$ ). Values indicate mean \pm SEM. Statistical values are from paired and unpaired Student's $t$ tests. $\mathrm{NE}_{\mathrm{v}}$, concentration of $\mathrm{NE}$ in mesenteric vein; $\mathrm{NE}_{\mathbf{a}}$, concentration of NE in aorta; $Q$, mesenteric plasma flow. 
significantly different in sham-operated and $2 \mathrm{~K}-1 \mathrm{C}$ rats that did not receive 1-Sar-8-Ile-AII. However, in the experiments in which NE neuronal spillover was determined, technical difficulties rendered comparisons between $2 \mathrm{~K}-1 \mathrm{C}$ and sham-operated animals somewhat meaningless. In this experiment, it was not possible to apply the stimulating electrodes snugly around the mesenteric artery because of the intramesenteric artery needle and because a polyethylene cannula was not in the lumen to provide mechanical support for the electrode. Therefore, the number of sympathetic nerve fibers stimulated varied greatly from animal to animal. This was especially true in the $2 \mathrm{~K}-1 \mathrm{C}$ animals where formation of adhesions in the peritoneal cavity, due to the silver clip, reduced the number of nerve fibers that could be stimulated with a loosely applied periarterial electrode. Therefore, the number of sympathetic nerve fibers stimulated in $2 \mathrm{~K}-1 \mathrm{C}$ rats was, in all probability, less than the number of fibers stimulated in sham-operated animals.

Our data also demonstrate that the vascular responsiveness to $\mathrm{NE}$ is enhanced in renovascular hypertension. This no doubt contributes to the overall enhancement of neurotransmission in renovascular hypertensive rats. However, exactly how this enhancement of responses to NE is mediated is unclear. One possibility is that nonspecific hypertension-induced alterations in blood vessel reactivity to vasoconstrictors is responsible. Another explanation for enhancement of NE responses in renovascular hypertension is that $\mathrm{AII}$ increases the vascular sensitivity to NE and/or inhibits NE uptake. This latter hypothesis would explain the similarity between the effects of exogenous AII and renovascular hypertension on vascular responses to nerve stimulation and NE (compare Figs. 7 and 10). However, this conclusion is apparently inconsistent with our observation that a 30 -min infusion of 1-Sar-8-Ile-AII does not reduce vascular responses to $\mathrm{NE}$ in renovascular hypertensive rats. A possible explanation for this discrepancy is that the effects of chronic exposure of AII on vascular sensitivity to NE and NE uptake are not reversed by short-term antagonism of AII receptors. That this might be the case is suggested by our observation that it is not possible to fully reverse the effects of even a short-term infusion of AII on NE responses with 1-Sar-8-Ile-AII (Fig. 6).

To summarize, the present data allow us to conclude that chronic renal artery stenosis enhances vascular responses to sympathetic nerve stimulation and, to a lesser extent, exogenous $\mathrm{NE}$; the enhancement of vascular responses to sympathetic nerve stimulation by renal artery stenosis is mediated in part by AIIinduced facilitation of NE release and in part by an enhanced sensitivity to NE; and the mechanism of the enhanced sensitivity to NE is unclear; however, a specific involvement of an AIImediated increase in vascular sensitivity and/or decrease in NE uptake cannot be excluded at the present time.

Another interesting question raised by our observations relates to the site of formation of the AII responsible for facilitating noradrenergic neurotransmission in renovascular hypertension. Unfortunately, the present data cannot distinguish between the possibilities that the AII responsible for facilitating neurotransmission is generated in the plasma or is formed in the blood vessel wall by the vascular renin-angiotensin system. Indeed, AII formation at both sites may be important.

Our study confirms and extends the previously published observations of Zimmerman and Kraft (26). These investigators examined the effects of acute aortic constriction on vascular responses to sympathetic nerve stimulation and exogenous NE in the blood-perfused dog paw. When plasma renin activity was increased by constricting a Blalock clamp cephalad to both renal arteries, vascular responses to sympathetic nerve stimulation, but not to exogenous NE, were potentiated. Further, this potentiation was reversed by AII-receptor blockade with saralasin. The authors concluded that acute renal ischemia activates the renal renin-angiotensin system sufficiently to potentiate depolarization-induced norepinephrine release from sympathetic nerve terminals. Our results differ from the findings of Zimmerman and Kraft mainly in that we observed enhancement of responses to both sympathetic nerve stimulation and exogenous NE. However, this difference is most likely due to the fact that we studied vascular responsiveness after chronic renal ischemia, whereas Zimmerman and Kraft examined the effects of acute renal ischemia. The important point of our study is that the previously observed acute prejunctional effects of endogenously generated AII can now be extended to the setting of sustained high renin renovascular hypertension. However, one caveat that must be considered is that both this study and the study by Zimmerman and Kraft were conducted in anesthetized animals. Inasmuch as anesthesia may alter the renin response to renal artery hypotension, it remains to be demonstrated whether or not these observations in anesthetized animals can be extended to the normal physiological state.

In summary, we observed that chronic renovascular hypertension was associated with an elevation in vascular responses to sympathetic nerve stimulation, and, to a lesser extent, exogenous NE. Further, antagonism of AII receptors attenuated the increase in vascular resistance and the increase in NE neuronal spillover induced by sympathetic nerve stimulation in renovascular hypertensive, but not normotensive, rats. We conclude that chronic renal artery stenosis enhances the vascular response to sympathetic nerve stimulation, and that this enhancement is mediated in part by AII-induced facilitation of NE release.

\section{Acknowledgments}

This work was supported by National Institutes of Health grant HL35909 and by a Grant-in-Aid from the American Heart Association with funds contributed in part by the Tennessee Affiliate. Edwin K. Jackson is an Established Investigator of the American Heart Association. This work was presented by Jeffrey B. Zimmerman, under the supervision of Dr. Jackson, as partial fulfillment of the requirements for the degree of Doctor of Philosophy in Pharmacology.

\section{References}

1. Sen, S., R. R. Smeby, F. M. Bumpus, and J. G. Turcotte. 1979. Role of renin-angiotensin system in chronic renal hypertensive rats. $\mathrm{Hy}$ pertension. 1:427-434.

2. DeForrest, J. M., R. C. Knappenberger, M. J. Antonaccio, R. A. Ferrone, and J. S. Creekmore. 1982. Angiotensin II is a necessary component for the development of hypertension in the two-kidney-one-clip rat. Am. J. Cardiol. 49:1515-1517.

3. Freeman, R. H., J. O. Davis, B. E. Watkins, G. A. Stephens, and J. M. DeForrest. 1979. Effects of continuous converting enzyme blockade on renovascular hypertension in the rat. Am. J. Physiol. 236:F21-F24.

4. Carretero, O. A., and O. P. Gulati. 1978. Effects of angiotensin antagonist in rats with acute, subacute, and chronic two-kidney renal hypertension. J. Lab. Clin. Med. 91:264-271.

5. Bing, R. F., G. I. Russell, J. D. Swales, and H. Thurston. 1981. Effect of 12-hour infusions of saralasin or captopril on blood pressure in hypertensive conscious rats. Relationship to plasma renin, duration of hypertension, and effect of unclippings. J. Lab. Clin. Med. 98:302310. 
6. Bengis, R. G., T. G. Coleman, D. B. Young, and R. E. McCaa. 1978. Long-term blockade of angiotensin formation in various normotensive and hypertensive rat models using converting enzyme inhibitor (SQ 14,225). Circ. Res. 43:I-45-I-53.

7. Bengis, R. G., and T. G. Coleman. 1979. Antihypertensive effect of prolonged blockade of angiotensin formation in benign and malignant, one- and two-kidney Goldblatt hypertensive rats. Clin. Sci. 57:53-62.

8. Thurston, H., R. F. Bing, and J. D. Swales. 1980. Reversal of twokidney one clip renovascular hypertension in the rat. Hypertension. 2: 256-265.

9. Wilson, C., and F. B. Byrom. 1941. The vicious circle in chronic Bright's disease. Experimental evidence from the hypertensive rat. Quart. J. Med. 10:65-93.

10. Thurston, H., R. F. Bing, E. S Marks, and J. D. Swales. 1980. Response of chronic renovascular hypertension to surgical correction or prolonged blockade of the renin-angiotensin system by two inhibitors in the rat. Clin. Sci. 58:15-20.

11. Dufau, M. L., and B. Kliman. 1968. Pharmacologic effects of angiotensin-II-amide on aldosterone and corticosterone secretion by the intact anesthetized rat. Endocrinology. 82:29-36.

12. Fitzsimons, J. T. 1978. Angiotensin, thirst, and sodium appetite: retrospect and prospect. Fed. Proc. 37:2669-2675.

13. Ausiello, D. A., J. I. Kreisberg, C. Roy, and M. J. Karnovsky. 1980. Contraction of cultured rat glomerular mesangial cells after stimulation with angiotensin II and arginine vasopressin. J. Clin. Invest. 65: 754-760.

14. Schuster, V. L., J. P. Kokko, and H. R. Jacobson. 1984. Angiotensin II directly stimulates sodium transport in rabbit proximal convoluted tubules. J. Clin. Invest. 73:507-515.

15. Harris, P. J., and L. G. Navar. 1985. Tubular transport responses to angiotensin. Am. J. Physiol. 248:F621-F628.

16. Buckley, J. P., and B. S. Jandhyala. 1977. Central cardiovascular effects of angiotensin. Life Sci. 20:1485-1494.

17. Zimmerman, B. G. 1978. Actions of angiotensin on adrenergic nerve endings, Fed. Proc. 37:199-202.

18. Faber, J. E., and M. J. Brody. 1984. Central nervous system action of angiotensin during onset of renal hypertension in awake rats. Am. J. Physiol. 247:H349-H360.

19. Zimmerman, B. G., and J. Gisslen. 1968. Pattern of renal vasoconstriction and transmitter release during sympathetic stimulation in presence of angiotensin and cocaine. J. Pharmacol. Exp. Ther. 163: 320-329.

20. Hughes, J., and R. H. Roth. 1971. Evidence that angiotensin enhances transmitter release during sympathetic nerve stimulation. $\mathbf{B r}$. J. Pharmacol. 41:239-255.

21. Peach, M. J., F. M. Bumpus, and P. A. Khairallah. 1969. Inhibition of norepinephrine uptake in hearts by angiotensin II and analogs. J. Pharmacol. Exp. Ther. 167:291-299.

22. Khairallah, P. A. 1972. Action of angiotensin on adrenergic nerve endings. Inhibition of norepinephrine uptake. Fed. Proc. 31:1351-1357.

23. Ekboir, A. S., and M. A. Enero. 1980. Pre- and postjunctional potentiation of the adrenergic neurotransmission by angiotensin II in the perfused rabbit kidney. Gen. Pharmacol. 11:395-402.

24. Yu, R., and C. J. Dickinson. 1971. The progressive pressor response to angiotensin in the rabbit-the role of the sympathetic nervous system. Arch. Int. Pharmacodyn. 191:24-36,

25. Zimmerman, B. G. 1962. Effect of acute sympathectomy on responses to angiotensin and norepinephrine. Circ. Res. 11:780-787.

26. Zimmerman, B. G., and E. Kraft. 1979. Blockade by saralasin of adrenergic potentiation induced by renin-angiotensin system. J. Pharmacol. Exp. Ther. 210:101-105.

27. Workman, R. J., C. R. Sussman, D. W. Burkitt, and G. W. Liddle. 1979. Circulatory levels of angiotensin I measured by radioimmunoassay in hypertensive subjects. J. Lab. Clin. Med. 93:847-856.

28. Jackson, E. K., and W. B. Campbell. 1980. The in situ blood perfused rat mesentery; a model for assessing modulation of adrenergic neurotransmission. Eur. J. Pharmacol. 66:217-224.

29. Peuler, J. D., and G. A. Johnson. 1977. Simultaneous single isotope radioenzymatic assay of plasma norepinephrine, epinephrine and dopamine. Life Sci. 21:625-636.

30. Saini, R. K., and P. Somani. 1979. Hemodynamic and regional blood flow studies in the normotensive and spontaneously hypertensive rat: application of the radioactive microsphere technique. J. Pharmacol. Methods. 2:357-369.

31. Benelli, G., D. D. Bella, and A. Gandini. 1964. Angiotensin and peripheral sympathetic nerve activity. Br. J. Pharmacol. 22:211-219.

32. Kadowitz, P. J., C. S. Sweet, and M. J. Brody. 1972. Influence of angiotensin I, angiotensin II and cocaine on adrenergic vasoconstrictor responses in the dog hindpaw. J. Pharmacol. Exp. Ther. 183:275-283.

33. Lokhandwala, M. F., E. Amelang, and J. P. Buckley. 1978. Facilitation of cardiac sympathetic function of angiotensin II: Role of presynaptic angiotensin receptors. Eur. J. Pharmacol. 52:405-409.

34. Schumann, H. J., K. Starke, and U. Werner. 1970. Interactions of inhibitors of noradrenaline uptake and angiotensin on the sympathetic nerves of the isolated rabbit heart. Br. J. Pharmacol. 39:390-397.

35. Starke, K. 1970. Interactions of angiotensin and cocaine on the output of noradrenaline from isolated rabbit hearts. Naunyn Schmiedebergs Arch. Pharmacol. 265:383-386.

36. Ackerly, J. A., A. L. Blumberg, G. Brooker, and M. J. Peach. 1978. Angiotensin II on the release of DBH and atrial cyclic AMP concentrations. Am. J. Physiol. 235:H281-H288.

37. Zimmerman, B. G. 1973. Blockade of adrenergic potentiating effect of angiotensin by 1-sar-8-ala-angiotensin II. J. Pharmacol. Exp. Ther. 185:486-492.

38. Malik, K. U., and A. Nasjletti. 1976. Facilitation of adrenergic transmission by locally generated angiotensin II in rat mesenteric arteries. Circ. Res. 38:26-30.

39. Campbell, W. B., and E. K. Jackson. 1979. Modulation of adrenergic transmission by angiotensins in the perfused rat mesentery. Am. J. Physiol. 236:H211-H217.

40. Jackson, E. K., and W. B. Campbell. 1979. Inhibition of neuronal noradrenaline uptake by angiotensin II in the rat mesentery. Can. J. Physiol. Pharmacol. 57:1443-1447. 